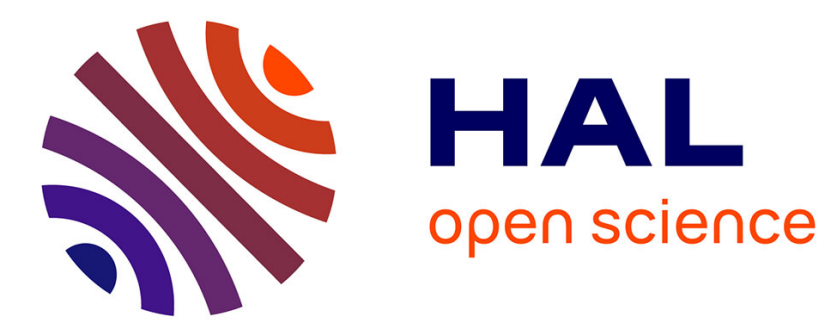

\title{
Loop transfer recovery designs with an unknown input reduced-order observer-based controller
}

\author{
Michel Zasadzinski, Mohamed Darouach, Mohamed Hayar
}

\section{To cite this version:}

Michel Zasadzinski, Mohamed Darouach, Mohamed Hayar. Loop transfer recovery designs with an unknown input reduced-order observer-based controller. International Journal of Robust and Nonlinear Control, 1995, 5 (7), pp.627-648. hal-00098148

\section{HAL Id: hal-00098148 \\ https://hal.science/hal-00098148}

Submitted on 24 Sep 2006

HAL is a multi-disciplinary open access archive for the deposit and dissemination of scientific research documents, whether they are published or not. The documents may come from teaching and research institutions in France or abroad, or from public or private research centers.
L'archive ouverte pluridisciplinaire HAL, est destinée au dépôt et à la diffusion de documents scientifiques de niveau recherche, publiés ou non, émanant des établissements d'enseignement et de recherche français ou étrangers, des laboratoires publics ou privés. 


\title{
LOOP TRANSFER RECOVERY DESIGNS WITH AN UNKNOWN INPUT REDUCED-ORDER OBSERVER-BASED CONTROLLER
}

\author{
M. Zasadzinski, M. Darouach, M. Hayar \\ C.R.A.N. (C.N.R.S. U.A. 821), Université de Nancy I \\ 186 rue de Lorraine, 54400 Cosnes et Romain, France
}

\begin{abstract}
This paper presents a new approach to the loop transfer recovery (LTR) in linear multivariable control systems, based on the unknown input reduced-order observer-based controller. Two parametrizations methods for all unknown input observers are presented, the first one is based on the matrix fraction description (MFD) and the second one is developed in $\mathrm{RH}_{\infty}$. The LTR for both minimum and non-minimum phase systems are considered. An exact recovery, based on the unknown input observer, is provided for minimum phase systems. For non-minimum phase systems, an approximate recovery is obtained by minimizing the $\mathrm{H}_{\infty}$ norm of the recovery matrix.
\end{abstract}

\section{Introduction}

Doyle [1] and Doyle and Stein [2] have analyzed the effects of observers on the robustness of LQG designs in a continuous time. They showed that, incorporating an observer in the LQ feedback law, can cause a loss of robustness of the LQ scheme. They proposed a linear quadratic gaussian loop transfer recovery (LQG/LTR) procedure as a multivariable robust control design tool to improve the classical LQG design [3]. The LQG/LTR design is based on the fact that, for minimum phase plants, the open loop transfer function of a state feedback system can be asymptotically recovered by the open loop transfer function of an output feedback system composed of an LQ regulator with a high gain observer. The robustness of the LQG/LTR synthesis is obtained when the phase and gain margins are close to those given by the LQ design.

Recently, a new method based on an $\mathrm{H}_{\infty}$ optimization has been introduced in the LTR problem [4][7]. The use of an $\mathrm{H}_{\infty}$ criterion for the LTR allows to improve the robustness properties of the feedback design [8]-[9]. In [1]-[7], all the LTR compensators are observer-based controllers. The reader can find the major aspects of the LTR theory in the recent book of Saberi et al. [10].

In this paper, we consider the problem of the loop transfer recovery at the input point (LTRI), and then from the robustness point of view, we make the assumption that the nominal plant model is perturbed by multiplicative uncertainties at the input. In the LTRI, the problem is reduced to an appropriate design of the observer part of the compensator such that the feedback system will have the same robustness as that of the direct state feedback system [10]. We assume that the gain matrix of the state feedback has been computed a priori with given robustness and performance specifications.

Generally in the LTR problem, the external disturbances which act upon the nominal system are not taken into account. These disturbances are unknown plant inputs, which can have a detrimental effect on 
the closed loop performances. On the other hand the problem of estimating the state of a linear timeinvariant system driven by both known and unknown inputs has received a considerable attention in the last decade [11], [12]. The problem is of a considerable importance since in practice there are many situations where plant disturbances are present, or some of the inputs of the system are inaccessible, and therefore a classical observer which assumes the knowledge of all inputs cannot be used.

This paper introduces an unknown input reduced-order observer-based controller in the LTR design. The observer is designed in the frequency domain using the matrix fraction description (MFD). To obtain the MFD representation of this observer, we present a straigthforward computational method which only requires operations on matrices of real numbers, rather than on polynomial matrices.

To design an LTR compensator, we consider the open loop transfer function as target loop transfer function. We show that, for minimum phase systems, an exact LTR can be obtained by considering the control input as an unknown input in the design of the observer. For non-minimum phase systems, an approximate LTR is obtained by minimizing the $\mathrm{H}_{\infty}$ norm of the recovery matrix. With an unknown input observer-based controller, we show that the recovery matrix is equal to the transfer matrix from the control input to the state estimate.

The paper is organized as follows. In section II, an unknown input reduced-order observer is parametrized and designed in the frequency domain. The necessary and sufficient conditions for the existence of this observer are given. The disturbance rejection with an unknown input observer-based controller is analyzed. In section III, we present LTR design methods for minimum and non-minimum phase systems. In section IV, two numerical examples are given to illustrate and to compare our method with other LTR methods presented in [2], [3] and [13].

In the sequel, we'll refer to the following finite dimensional linear time invariant system (FDLTI)

$$
\begin{aligned}
& \dot{\mathrm{x}}=\mathrm{Ax}+\mathrm{B}_{1} \mathrm{w}+\mathrm{B}_{2} \mathrm{u} \\
& \mathrm{z}=\mathrm{C}_{1} \mathrm{x} \\
& \mathrm{y}=\mathrm{C}_{2} \mathrm{x}
\end{aligned}
$$

where $\mathrm{x} \in \mathrm{R}^{\mathrm{n}}, \mathrm{w} \in \mathrm{R}^{\mathrm{m}}, \mathrm{u} \in \mathrm{R}^{\mathrm{q}}, \mathrm{z} \in \mathrm{R}^{\mathrm{k}}$ and $\mathrm{y} \in \mathrm{R}^{\mathrm{p}}$ are the state, the unknown external input, the control input, the controlled output and the measured output respectively with $\mathrm{p} \geq \mathrm{m}$ and $\mathrm{n}>\mathrm{q} . \mathrm{A}, \mathrm{B}_{1}, \mathrm{~B}_{2}$, $\mathrm{C}_{1}$ and $\mathrm{C}_{2}$ are constant matrices with appropriate dimensions. Without loss of generality, we assume that $\operatorname{rank}\left(\mathrm{B}_{1}\right)=\mathrm{m}$ and $\operatorname{rank}\left(\mathrm{C}_{2}\right)=\mathrm{p}$. The basic block diagram used in this paper has the following form

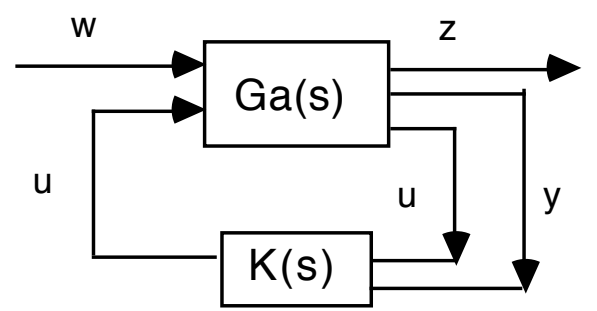

Figure $1:$ modified standard problem 
where $G_{a}(s)=\left[\begin{array}{cc}G_{11}(s) & G_{12}(s) \\ G_{21}(s) & G_{22}(s) \\ 0 & I_{q}\end{array}\right]$ is the generalized plant and $K(s)$ is an FDLTI controller. The proposed controller $\mathrm{K}(\mathrm{s})$ is designed to stabilize internally the closed loop transfer function $\mathrm{T}_{\mathrm{wz}}(\mathrm{s})$ from $\mathrm{w}$ to $\mathrm{z}$, and to recover the closed loop properties of a state feedback controller scheme in the full information case $\left(C_{2}=I_{n}\right.$ and $\left.n=p\right)$.

In the sequel, we make the following assumptions.

A-1 : $G_{21}(s)$ is of full column rank for almost all complex numbers $s$,

A-2 : triplet $\left(A, B_{1}, C_{2}\right)$ has no unstable invariant zero, i.e. $G_{21}(s)$ is minimum phase,

A-3 : $\operatorname{rank}\left(C_{2} B_{1}\right)=\operatorname{rank}\left(B_{1}\right)=m$,

A-4 : $\left(A, B_{2}\right)$ is stabilizable and $\left(C_{2}, A\right)$ is detectable.

Unlike $\mathrm{G}_{21}(\mathrm{~s})$, the system $\left[\mathrm{G}_{21}(\mathrm{~s}) \mathrm{G}_{22}(\mathrm{~s})\right]$ can be minimum or non-minimum phase.

In this paper, we consider that the compensator $\mathrm{K}(\mathrm{s})$ is an unknown input observer-based controller. Before designing the observer, one must compute a state feedback control law $\mathrm{u}=\mathrm{F} \mathrm{x}$ which stabilizes internally the system (1) (see [3], [9] and [14]). In the sequel, we assume that the gain matrix F is known.

\section{Unknown input reduced-order observer design in the frequency domain}

This section is divided in fourth sub-sections. In the first sub-section, we present a parametrization, in a matrix fraction description (MFD), of all unknown input observers for system (1) in the frequency domain. In the second sub-section, we propose a straightforward procedure, based on this parametrization, to design this observer. In the third sub-section, we present a parametrization of all unknown input observers for system (1) in $\mathrm{RH}_{\infty}$. This parametrization in $\mathrm{RH}_{\infty}$ is used in section III to achieve an exact or an approximate LTR design. Finally in the last sub-section, the obtained disturbance rejection is analyzed.

\section{a. Parametrization of unknown input observers from MFD}

The system described by

$$
x_{e}(s)=N_{y}(s) y(s)+N_{u}(s) u(s)
$$

is called an unknown input observer for system (1) if the state estimate $x_{e}$ converges asymptotically to the state $\mathrm{x}$ by using the control input $\mathrm{u}$ and the measured output $\mathrm{y}$, without the knowledge of the external disturbance w.

Hautus [15] has formulated, in the frequency domain, the necessary and sufficient conditions for the existence of a stable unknown input observer for system (1). These conditions are given in the two following theorems. 


\section{Theorem 1 [15]}

A stable unknown input observer for system (1) is determined by relation (2) if and only if there exist stable matrices $\mathrm{M}(\mathrm{s})$ and $\mathrm{N}(\mathrm{s})$ such that $\mathrm{N}(\mathrm{s})$ is proper and

$$
\left[\begin{array}{ll}
M(s) & N(s)
\end{array}\right]\left[\begin{array}{ccc}
\mathrm{sI}_{\mathrm{n}}-\mathrm{A} & -\mathrm{B}_{1} & -\mathrm{B}_{2} \\
\mathrm{C}_{2} & 0 & 0 \\
0 & 0 & \mathrm{I}_{\mathrm{q}}
\end{array}\right]=\left[\begin{array}{lll}
\mathrm{I}_{\mathrm{n}} & 0 & 0
\end{array}\right]
$$

where $\mathrm{N}(\mathrm{s})=\left[\begin{array}{ll}\mathrm{N}_{\mathrm{y}}(\mathrm{s}) & \mathrm{N}_{\mathrm{u}}(\mathrm{s})\end{array}\right]$

\section{Theorem 2 [15]}

The unknown input observer described in theorem 1 exists if and only if assumptions A-2 and A-3 are satisfied.

The state space system (1) can be written in Laplace transform as

$$
\left[\begin{array}{ccc}
\mathrm{sI}_{\mathrm{n}}-\mathrm{A} & -\mathrm{B}_{1} & -\mathrm{B}_{2} \\
\mathrm{C}_{2} & 0 & 0 \\
0 & 0 & \mathrm{I}_{\mathrm{q}}
\end{array}\right]\left[\begin{array}{l}
\mathrm{x} \\
\mathrm{w} \\
\mathrm{u}
\end{array}\right]=\left[\begin{array}{l}
\mathrm{x}_{0} \\
\mathrm{y} \\
\mathrm{u}
\end{array}\right]
$$

where $\mathrm{x}_{0}$ is the initial state vector.

Combining equations (2)-(4), we obtain

$$
x=M(s) x_{0}+N_{y}(s) y+N_{u}(s) u=M(s) x_{0}+x_{e}
$$

Then $\left(\mathrm{x}-\mathrm{x}_{\mathrm{e}}\right)$ converges to zero since $\mathrm{M}(\mathrm{s})$ is stable. The FLDTI system $\mathrm{K}(\mathrm{s})=\mathrm{F} \mathrm{N}(\mathrm{s})$ is an unknown input observer-based controller for the modified standard problem in figure 1 . The following theorem presents the separation principle for such controllers.

\section{Theorem 3}

The closed loop transfer function of system in figure 1 is internally stable for $\mathrm{K}(\mathrm{s})=\mathrm{F} \mathrm{N}(\mathrm{s})$ if and only if $\mathrm{M}(\mathrm{s}), \mathrm{N}(\mathrm{s})$ and $\left(\mathrm{sI}_{\mathrm{n}}-\mathrm{A}-\mathrm{B}_{2} \mathrm{~F}\right)^{-1}$ are stable, where $\mathrm{M}(\mathrm{s})$ and $\mathrm{N}(\mathrm{s})$ are given in theorem 1 .

\section{Proof}

From (3)-(5), the state estimation error is given by $e=x-x_{e}=M(s) x_{0}$ where $M(s)$ is the strictly proper transfer matrix given by

$$
M(s)=\left(I_{n}-N_{y}(s) C_{2}\right)(s I-A)^{-1}
$$

Let $[\Phi, \mathrm{G}, \mathrm{H}, 0]$ be a state-space realization of $\mathrm{M}(\mathrm{s})$, and let $\mathrm{v}$ be a state vector associated with the system M(s). By using equations (1), (2), (4), (5) and the state feedback gain F, the closed loop system has the following state-space form 


$$
\left\{\begin{array}{l}
\dot{x}=A x+B_{1} w+B_{2} u \\
\dot{v}=\Phi v+G x_{0} \\
x_{e}=x-H v \\
u=F x_{e}
\end{array}\right.
$$

The closed loop state matrix $\mathrm{A}_{\mathrm{cl}}$

$$
A_{c l}=\left[\begin{array}{cc}
A+B_{2} F & -B_{2} F H \\
0 & \Phi
\end{array}\right]
$$

is internally stable under the assumptions of theorem 3 .

To obtain an MFD representation of the transfer function matrices M(s) and N(s), we can write equation (3) as

$$
\left[\mathrm{M} \_(s) N_{-y}(s) N_{-u}(s) D_{-}(s)\right]\left[\begin{array}{ccc}
\mathrm{sI}_{\mathrm{n}}-\mathrm{A} & -\mathrm{B}_{1} & -\mathrm{B}_{2} \\
\mathrm{C}_{2} & 0 & 0 \\
0 & 0 & \mathrm{I}_{\mathrm{q}} \\
-\mathrm{I}_{\mathrm{n}} & 0 & 0
\end{array}\right]=\left[\begin{array}{llll}
0 & 0 & 0
\end{array}\right]
$$

where $D_{-}^{-1}(s)\left[M_{-}(s) N_{-y}(s) N_{-u}(s)\right]$ is a MFD representation of $\left[M(s) N_{y}(s) N_{u}(s)\right]$. The solution of (7) can be obtained from the left kernel of a polynomial matrix. This kernel can be easily parametrized if we consider the following polynomial matrix factorization

$$
\mathrm{U}_{1}(\mathrm{~s})\left[\begin{array}{ccc}
\mathrm{sI}_{\mathrm{n}}-\mathrm{A} & -\mathrm{B}_{1} & -\mathrm{B}_{2} \\
\mathrm{C}_{2} & 0 & 0 \\
0 & 0 & \mathrm{I}_{\mathrm{q}} \\
-\mathrm{I}_{\mathrm{n}} & 0 & 0
\end{array}\right] \mathrm{U}_{2}=\left[\begin{array}{ccc}
\mathrm{I}_{\mathrm{n}} & 0 & 0 \\
0 & \mathrm{I}_{\mathrm{q}} & 0 \\
0 & 0 & \mathrm{I}_{\mathrm{m}} \\
0 & 0 & 0 \\
0 & 0 & 0
\end{array}\right]
$$

where $\mathrm{U}_{1}(\mathrm{~s})$ and $\mathrm{U}_{2}$ are two unimodular matrices given by

$$
\mathrm{U}_{1}(\mathrm{~s})=\left[\begin{array}{cccc}
0 & 0 & 0 & -\mathrm{I}_{\mathrm{n}} \\
0 & 0 & \mathrm{I}_{\mathrm{q}} & 0 \\
\mathrm{P}_{1} & 0 & \mathrm{P}_{1} \mathrm{~B}_{2} & \mathrm{P}_{1}\left(\mathrm{sI}_{\mathrm{n}}-\mathrm{A}\right) \\
\mathrm{P}_{2} & 0 & \mathrm{P}_{2} \mathrm{~B}_{2} & \mathrm{P}_{2}\left(\mathrm{sI}_{\mathrm{n}}-\mathrm{A}\right) \\
0 & \mathrm{I}_{\mathrm{p}} & 0 & \mathrm{C}_{2}
\end{array}\right] \text { and } \mathrm{U}_{2}=\left[\begin{array}{ccc}
\mathrm{I}_{\mathrm{n}} & 0 & 0 \\
0 & 0 & \mathrm{I}_{\mathrm{m}} \\
0 & \mathrm{I}_{\mathrm{q}} & 0
\end{array}\right]
$$

with

$$
P_{1}=-\left(B_{1}^{T} B_{1}\right)^{-1} B_{1}^{T}
$$

and 


$$
\mathrm{P}_{2} \mathrm{~B}_{1}=0, \operatorname{det}\left(\left[\begin{array}{l}
\mathrm{P}_{1} \\
\mathrm{P}_{2}
\end{array}\right]\right) \neq 0
$$

Matrix $\mathrm{U}_{1}(\mathrm{~s})$ is unimodular since $\operatorname{det}\left(\mathrm{U}_{1}(\mathrm{~s})\right)= \pm \operatorname{det}\left(\left[\begin{array}{l}\mathrm{P}_{1} \\ \mathrm{P}_{2}\end{array}\right]\right)$. From (7)-(9), we obtain

$$
\begin{aligned}
& D_{-}(s)=a_{1}(s) P_{2}\left(s I_{n}-A\right)+a_{2}(s) C_{2} \\
& M_{-}(s)=a_{1}(s) P_{2} \\
& N_{-y}(s)=a_{2}(s) \\
& N_{-u}(s)=a_{1}(s) P_{2} B_{2}
\end{aligned}
$$

where $a_{1}(s)$ and $a_{2}(s)$ are arbitrary polynomial matrices, of dimensions (n,n-m) and (n,p) respectively, such that D_(s) is a non-singular polynomial matrix and det(D_(s)) has all its roots strictly in the left half complex plane. Equations (10.1), (10.3) and (10.4) define the MFD representation of an unknown input observer for system (1). Polynomial matrices $\mathrm{a}_{1}(\mathrm{~s})$ and $\mathrm{a}_{2}(\mathrm{~s})$ give a parametrization of all unknown input observers for system (1) in a matrix fraction description. Before presenting the design procedure for the unknown input reduced-order observer, we prove the following result.

\section{Theorem 4}

Under the assumption A-2, the fixed poles of all unknown input observers are stable.

\section{Proof}

From assumption A-2 we have

$$
\operatorname{rank}\left(\left[\begin{array}{cc}
\mathrm{sI}_{\mathrm{n}}-\mathrm{A} & -\mathrm{B}_{1} \\
\mathrm{C}_{2} & 0
\end{array}\right]\right)<\mathrm{n}+\mathrm{m} \operatorname{or} \operatorname{rank}\left(\left[\begin{array}{ccc}
\mathrm{sI}_{\mathrm{n}}-\mathrm{A} & -\mathrm{B}_{1} & -\mathrm{B}_{1} \\
\mathrm{C}_{2} & 0 & 0 \\
0 & 0 & \mathrm{I}_{\mathrm{q}}
\end{array}\right]\right)<\mathrm{n}+\mathrm{m}+\mathrm{q}, \forall \mathrm{s} \in \mathbb{C}, \operatorname{Re}(\mathrm{s}) \geq 0
$$

Define the following non-singular matrices

$$
\mathrm{V}_{1}=\left[\begin{array}{cc}
\mathrm{P}_{1} & 0 \\
\mathrm{P}_{2} & 0 \\
0 & \mathrm{I}_{\mathrm{q}}
\end{array}\right] \text { and } \mathrm{V}_{2}=\left[\begin{array}{cc}
\mathrm{I}_{\mathrm{n}} & 0 \\
\mathrm{P}_{1}\left(\mathrm{sI}_{\mathrm{n}}-\mathrm{A}\right) & \mathrm{I}_{\mathrm{m}}
\end{array}\right]
$$

Then we have

$$
\begin{aligned}
\operatorname{rank}\left(\left[\begin{array}{cc}
\mathrm{sI}_{\mathrm{n}}-\mathrm{A} & -\mathrm{B}_{1} \\
\mathrm{C}_{2} & 0
\end{array}\right]\right) & =\operatorname{rank}\left(\mathrm{V}_{1}\left[\begin{array}{cc}
\mathrm{sI}_{\mathrm{n}}-\mathrm{A} & -\mathrm{B}_{1} \\
\mathrm{C}_{2} & 0
\end{array}\right] \mathrm{V}_{2}\right) \\
& =\operatorname{rank}\left(\left[\begin{array}{cc}
0 & \mathrm{I}_{\mathrm{m}} \\
\mathrm{P}_{2}\left(\mathrm{sI}_{\mathrm{n}}-\mathrm{A}\right) & 0 \\
\mathrm{C}_{2} & 0
\end{array}\right]\right)
\end{aligned}
$$




$$
=\operatorname{rank}\left(\left[\begin{array}{c}
0 \\
\mathrm{P}_{2}\left(\mathrm{sI}_{\mathrm{n}}-\mathrm{A}\right) \\
\mathrm{C}_{2}
\end{array}\right]\right)+\mathrm{m}, \forall \mathrm{s} \in \mathbb{C}, \operatorname{Re}(\mathrm{s}) \geq 0
$$

Now from (10.1), we have

$$
\text { D_(s) }=\left[\begin{array}{lll}
0 & a_{1}(s) & a_{2}(s)
\end{array}\right]\left[\begin{array}{c}
0 \\
P_{2}\left(s I_{n}-A\right) \\
C_{2}
\end{array}\right]
$$

From (11) and (12), it is easy to deduce the result of theorem 4.

\section{b. Design procedure of the unknown input reduced-order observer}

The previous MFD parametrization is used to derive a straightforward procedure to design an unknown input observer of minimal order.

Since we have $x \in R^{n}, y \in R^{p}$ and $\operatorname{rank}\left(C_{2}\right)=p$, then the minimal order of the unknown input observer is $(n-p)$, i.e. we must find $D_{-}(s)$ such that $\operatorname{degree}\left(\operatorname{det}\left(D_{-}(s)\right)\right)=n-p$. If $\operatorname{degree}\left(a_{1}(s)\right)=$ degree $\left(\mathrm{a}_{2}(\mathrm{~s})\right)=0$, the polynomial equation $(10.1)$ can be written as

$$
\left[\begin{array}{ll}
\mathrm{a}_{1} & \mathrm{a}_{2}
\end{array}\right]\left[\begin{array}{cc}
\mathrm{P}_{2} & -\mathrm{P}_{2} \mathrm{~A} \\
0 & \mathrm{C}_{2}
\end{array}\right]=\left[\begin{array}{ll}
\mathrm{d}_{0} & \mathrm{~d}_{1}
\end{array}\right]
$$

where

$$
\text { D_(s) }=\mathrm{s} \mathrm{d}_{0}+\mathrm{d}_{1}
$$

Equation (13.1) has a solution if and only if

$$
\operatorname{Im}\left(\left[\begin{array}{cc}
\mathrm{P}_{2} & -\mathrm{P}_{2} \mathrm{~A} \\
0 & \mathrm{C}_{2}
\end{array}\right]^{\mathrm{T}}\right) \supset \operatorname{Im}\left(\left[\begin{array}{ll}
\mathrm{d}_{0} & \mathrm{~d}_{1}
\end{array}\right]^{\mathrm{T}}\right)
$$

where $\operatorname{Im}(\mathrm{A})$ denotes the column space of matrix $\mathrm{A}$.

Define the non-singular matrices $\mathrm{T}_{1}$ and $\mathrm{T}_{2}$ such that

$$
\begin{aligned}
& \mathrm{C}_{2} \mathrm{~T}_{1}^{-1}=\left[\begin{array}{ll}
0 & \mathrm{I}_{\mathrm{p}}
\end{array}\right] \\
& \mathrm{T}_{2} \mathrm{P}_{2} \mathrm{~T}_{1}^{-1}=\left[\begin{array}{cc}
\mathrm{I}_{\mathrm{n}-\mathrm{p}} & \alpha_{2} \\
0 & \gamma_{2}
\end{array}\right]
\end{aligned}
$$

Matrix $\mathrm{P}_{2}$ being of full row rank (see (9.3)), matrix $\mathrm{T}_{2}$ in equation (15.2) exists if and only if assumption A-3 is satisfied. With matrices $\mathrm{T}_{1}$ and $\mathrm{T}_{2}$, we obtain

$$
\left[\begin{array}{cc}
\mathrm{T}_{2} & 0 \\
0 & \mathrm{I}_{\mathrm{p}}
\end{array}\right]\left[\begin{array}{cc}
\mathrm{P}_{2} & -\mathrm{P}_{2} \mathrm{~A} \\
0 & \mathrm{C}_{2}
\end{array}\right]\left[\begin{array}{cc}
\mathrm{T}_{1}^{-1} & 0 \\
0 & \mathrm{~T}_{1}^{-1}
\end{array}\right]=\left[\begin{array}{cccc}
\mathrm{I}_{\mathrm{n}-\mathrm{p}} & \alpha_{2} & \alpha_{3} & \alpha_{4} \\
0 & \gamma_{2} & \gamma_{3} & \gamma_{4} \\
0 & 0 & 0 & \mathrm{I}_{\mathrm{p}}
\end{array}\right]
$$


Define matrices $a_{-1}, a_{-2}, Z, d_{-1}$ and $d_{-2}$ such that

$$
\left[\begin{array}{ll}
a_{-1} & a_{-2}
\end{array}\right]=\left[\begin{array}{ll}
a_{1} & a_{2}
\end{array}\right]\left[\begin{array}{cc}
T_{2}^{-1} & 0 \\
0 & I_{p}
\end{array}\right]\left[\begin{array}{ccc}
I_{n-p} & -Z & 0 \\
0 & I_{p-m} & 0 \\
0 & 0 & I_{p}
\end{array}\right]
$$

and

$$
\left[\begin{array}{ll}
\mathrm{d}_{-0} & \mathrm{~d}_{-1}
\end{array}\right]=\left[\begin{array}{ll}
\mathrm{d}_{0} & \mathrm{~d}_{1}
\end{array}\right]\left[\begin{array}{cc}
\mathrm{T}_{1}^{-1} & 0 \\
0 & \mathrm{~T}_{1}^{-1}
\end{array}\right]
$$

With these notations, equation (13.1) is equivalent to

$$
\left[\begin{array}{ll}
a_{-1} & a_{-2}
\end{array}\right]\left[\begin{array}{ccc}
I_{n-p} & Z & 0 \\
0 & I_{p-m} & 0 \\
0 & 0 & I_{p}
\end{array}\right]\left[\begin{array}{cccc}
I_{n-p} & \alpha_{2} & \alpha_{3} & \alpha_{4} \\
0 & \gamma_{2} & \gamma_{3} & \gamma_{4} \\
0 & 0 & 0 & I_{p}
\end{array}\right]=\left[\begin{array}{ll}
d_{-0} & d_{-1}
\end{array}\right]
$$

To satisfy condition (14), we can choose $\mathrm{d}_{-0}$ and $\mathrm{d}_{-1}$ as follows

$$
d_{-0}=\left[\begin{array}{cc}
I_{n-p} & \alpha_{2}+Z \gamma_{2} \\
0 & 0
\end{array}\right]
$$

and

$$
\mathrm{d}_{-1}=\left[\begin{array}{cc}
\alpha_{3}+\mathrm{Z} \gamma_{3} & \alpha_{4}+\mathrm{Z} \gamma_{4} \\
0 & \mathrm{I}_{\mathrm{p}}
\end{array}\right]
$$

Hence, the polynomial matrix D_(s) is given by

$$
D_{-}(\mathrm{s})=\left[\begin{array}{cc}
\mathrm{sI}_{\mathrm{n}-\mathrm{p}}+\alpha_{3}+\mathrm{Z} \gamma_{3} & \mathrm{~s}\left(\alpha_{2}+\mathrm{Z} \gamma_{2}\right)+\left(\alpha_{4}+\mathrm{Z} \gamma_{4}\right) \\
0 & \mathrm{I}_{\mathrm{p}}
\end{array}\right] \mathrm{T}_{1}
$$

and the (n-p) poles of the unknown input reduced-order observer are the eigenvalues of $\left(-\alpha_{3}-Z \gamma_{3}\right)$. The free parameter $\mathrm{Z}$ is of dimension (n-p,p-m). If $\mathrm{p}=\mathrm{m}$, there is no freedom in the assignment of the observer poles, the stability of the observer being guaranteed by theorem 4 .

Finally, by inserting relations (13) and (16)-(18) into equations (10.1), (10.3) and (10.4), the MFD representation of this observer is given by

$$
\begin{aligned}
& D_{-}(s)=\left[\begin{array}{cc}
{\left[I_{n-p}\right.} & Z \\
C_{2} T_{2} P_{2}\left(s_{n}-A\right)
\end{array}\right] \\
& N_{-y}(s)=N_{-y}=\left[\begin{array}{c}
0 \\
I_{p}
\end{array}\right] \\
& N_{-u}(s)=N_{-u}=\left[\begin{array}{cc}
{\left[\begin{array}{cc}
I_{n-p} & Z
\end{array}\right] T_{2} P_{2} B_{2}} \\
0
\end{array}\right]
\end{aligned}
$$


We can now propose the following design procedure.

1) Compute matrices $P_{2}, T_{1}$ and $T_{2}$ defined in equations (9.3), (15.1) and (15.2).

2) Compute matrices $\alpha_{3}$ and $\gamma_{3}$ from equation (16).

3) Choose matrix $Z$ by a pole-placement procedure. The poles of the observer are the eigenvalues of $\left(-\alpha_{3}-Z \gamma_{3}\right)$. The pair $\left(\alpha_{3}, \gamma_{3}\right)$ is detectable if and only if assumption A-2 is satisfied (see theorem 4).

4) Matrices $D_{-}(\mathrm{s}), \mathrm{N}_{-\mathrm{y}}$ and $\mathrm{N}_{-\mathrm{u}}$ are given by relations (22.1), (22.2) and (22.3).

The proposed computational method requires only operations on matrices of real numbers. The transfer matrices of this observer, $\mathrm{N}_{\mathrm{y}}(\mathrm{s})$ and $\mathrm{N}_{\mathrm{u}}(\mathrm{s})$, are given by

$$
\mathrm{N}_{\mathrm{y}}(\mathrm{s})=\mathrm{T}_{1}^{-1}\left[\begin{array}{c}
-\left(\mathrm{sI} \mathrm{I}_{\mathrm{n}-\mathrm{p}}+\alpha_{3}+\mathrm{Z} \gamma_{3}\right)^{-1}\left(\mathrm{~s}\left(\alpha_{2}+\mathrm{Z} \gamma_{2}\right)+\left(\alpha_{4}+\mathrm{Z} \gamma_{4}\right)\right) \\
\mathrm{I}_{\mathrm{p}}
\end{array}\right]
$$

and

$$
\mathrm{N}_{\mathrm{u}}(\mathrm{s})=\mathrm{T}_{1}^{-1}\left[\begin{array}{c}
\left(\mathrm{sI} \mathrm{n}_{\mathrm{p}}+\alpha_{3}+\mathrm{Z} \gamma_{3}\right)^{-1}\left(\mathrm{~B}_{21}+\left(\alpha_{2}+\mathrm{Z} \gamma_{2}\right) \mathrm{B}_{22}\right) \\
0
\end{array}\right]
$$

where matrices $\mathrm{B}_{21}$ and $\mathrm{B}_{22}$ are defined by

$$
\left[\begin{array}{l}
\mathrm{B}_{21} \\
\mathrm{~B}_{22}
\end{array}\right]=\mathrm{T}_{1} \mathrm{~B}_{2}
$$

\section{c. Parametrization of unknown input observers in $\mathbf{R H}_{\infty}$}

Now, we present a parametrization of this observer in $\mathrm{RH}_{\infty}$. This parametrization will be used to achieve an exact or an approximate LTR design. Let $\mathrm{N}(\mathrm{s})$ be given in theorem 1, our aim is to parametrize all unknown input observer for system (1) in an affine form

$$
\mathrm{L}(\mathrm{s})=\mathrm{N}(\mathrm{s})+\mathrm{Q}(\mathrm{s}) \mathrm{W}(\mathrm{s})
$$

where $\mathrm{L}(\mathrm{s})$ is the parametrized unknown input observer, $\mathrm{Q}(\mathrm{s})$ is an arbitrary transfer matrix of dimension (n,p-m) belonging to $\mathrm{RH}_{\infty}$, and $\mathrm{W}(\mathrm{s})$ is a stable transfer matrix of dimension (p-m,p+q) chosen such that theorem 1 remains true if we replace $\mathrm{N}(\mathrm{s})$ by $\mathrm{L}(\mathrm{s})$ in (3) (the construction of $\mathrm{W}(\mathrm{s})$ is detailed in (27) and (28)). $\mathrm{N}(\mathrm{s})$ is called the central unknown input observer. The parametrization (25) is reduced to finding the unknown parameter $\mathrm{Q}(\mathrm{s})$ such that $\mathrm{L}(\mathrm{s}) \in \mathrm{RH}_{\infty}$.

The transfer matrix W(s) can be obtained as follows. From (3) and (7) we have

$$
\mathrm{N}(\mathrm{s})=\left[\mathrm{N}_{\mathrm{y}}(\mathrm{s}) \mathrm{N}_{\mathrm{u}}(\mathrm{s})\right]=\mathrm{D}_{-}^{-1}(\mathrm{~s})\left[\mathrm{N}_{-\mathrm{y}}(\mathrm{s}) \mathrm{N}_{-\mathrm{u}}(\mathrm{s})\right]
$$

where $\mathrm{D}_{-}(\mathrm{s}), \mathrm{N}_{-\mathrm{y}}(\mathrm{s})$ and $\mathrm{N}_{-\mathrm{u}}(\mathrm{s})$ are given by equations (10.1), (10.3) and (10.4). A particular expression for polynomial matrices $D_{-}(s), N_{-y}(s)$ and $N_{-u}(s)$ is given in $(22)$ where $\operatorname{det}\left(D_{-}(s)\right)$ is of minimal order. 
Let $D_{t}(s)$ and $N_{t}(s)$ be polynomial matrices of dimensions (p-m,p-m) and $(p-m, n+p+q)$ respectively, such that $\mathrm{D}_{\mathrm{t}}(\mathrm{s})$ is non-singular, $\operatorname{det}\left(\mathrm{D}_{\mathrm{t}}(\mathrm{s})\right)$ has all its roots strictly inside the left half plane and

$$
\mathrm{N}_{\mathrm{t}}(\mathrm{s})\left[\begin{array}{ccc}
\mathrm{sI}_{\mathrm{n}}-\mathrm{A} & -\mathrm{B}_{1} & -\mathrm{B}_{2} \\
\mathrm{C}_{2} & 0 & 0 \\
0 & 0 & \mathrm{I}_{\mathrm{q}}
\end{array}\right]=\left[\begin{array}{lll}
0 & 0 & 0
\end{array}\right]
$$

Remark : if $\mathrm{p}=\mathrm{m}$, we have $\mathrm{L}(\mathrm{s})=\mathrm{N}(\mathrm{s})$.

A straightforward algorithm to compute the kernel of a polynomial matrix, based on the resultant, is proposed by Barnett [16]. Hence, for system (1), all the unknown input observers L(s) are given by (25), where the matrix $\mathrm{W}(\mathrm{s})$ is

$$
\mathrm{W}(\mathrm{s})=\mathrm{D}_{\mathrm{t}}^{-1}(\mathrm{~s}) \mathrm{N}_{\mathrm{t} 2}(\mathrm{~s})
$$

The matrix $\mathrm{N}_{\mathrm{t} 2}(\mathrm{~s})$ can be obtained by selecting the $(\mathrm{p}+\mathrm{q})$ last columns of $\mathrm{N}_{\mathrm{t}}(\mathrm{s})$.

\section{d. Disturbance rejection with an unknown input observer-based controller}

Before using this parametrization in an LTR design, we analyze the disturbance rejection which can be achieved with an unknown input observer-based controller. The closed loop system described by the modified standard problem in figure 1 can be depicted as shown in figure 2.

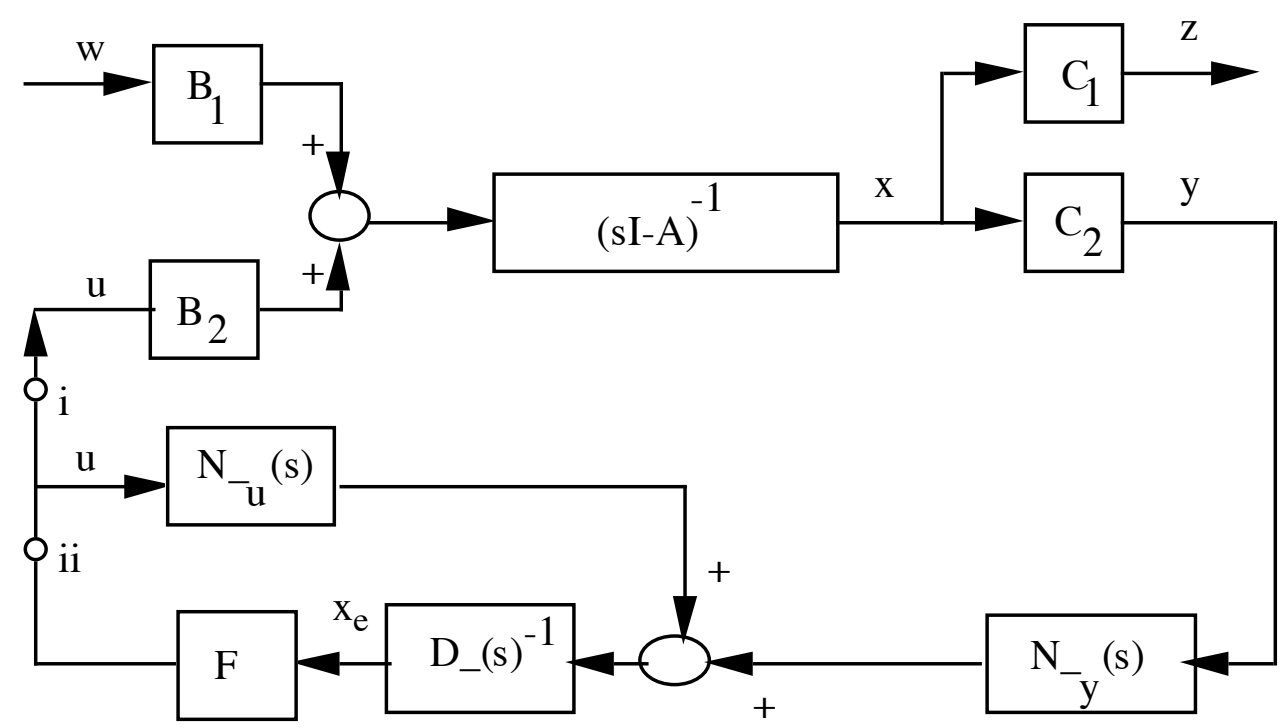

Figure 2 : closed loop with an unknown input observer-based controller

The controller $\mathrm{K}(\mathrm{s})$ is given by

$$
\mathrm{K}(\mathrm{s})=\mathrm{F} \mathrm{N}(\mathrm{s})=\mathrm{F}\left[\mathrm{N}_{\mathrm{y}}(\mathrm{s}) \mathrm{N}_{\mathrm{u}}(\mathrm{s})\right]
$$

Let $\mathrm{T}_{\mathrm{wu}}(\mathrm{s})$ and $\mathrm{T}_{\mathrm{wz}}(\mathrm{s})$ be the transfer matrices from external disturbance $\mathrm{w}$ to the control input $\mathrm{u}$ and the controlled output $\mathrm{z}$ respectively. $\mathrm{T}_{\mathrm{wu}}(\mathrm{s})$ is given by 


$$
\mathrm{T}_{\mathrm{wu}}(\mathrm{s})=\left(\mathrm{I}_{\mathrm{q}}-\mathrm{FD}_{-}^{-1}(\mathrm{~s})\left(\mathrm{N}_{-\mathrm{u}}(\mathrm{s})+\mathrm{N}_{-\mathrm{y}}(\mathrm{s}) \mathrm{C}_{2}\left(\mathrm{sI}_{\mathrm{n}}-\mathrm{A}\right)^{-1} \mathrm{~B}_{2}\right)\right)^{-1} \mathrm{FD}_{-}^{-1}(\mathrm{~s}) \mathrm{N}_{-\mathrm{y}}(\mathrm{s}) \mathrm{C}_{2}\left(\mathrm{sI}_{\mathrm{n}}-\mathrm{A}\right)^{-1} \mathrm{~B}_{1}
$$

For a direct state feedback system, this transfer matrix is given by

$$
\mathrm{T}_{\mathrm{Fwu}}(\mathrm{s})=\left(\mathrm{I}_{\mathrm{q}}-\mathrm{F}\left(\mathrm{sI} \mathrm{I}_{\mathrm{n}}-\mathrm{A}\right)^{-1} \mathrm{~B}_{2}\right)^{-1} \mathrm{~F}\left(\mathrm{sI}_{\mathrm{n}}-\mathrm{A}\right)^{-1} \mathrm{~B}_{1}
$$

By using equation (7), which is equivalent to

$$
\begin{aligned}
& M \_(s)\left(s_{n}-A\right)+N_{-y}(s) C_{2}=D_{-}(s) \\
& M \_(s) B_{1}=0 \\
& M \_(s) B_{2}=N_{-u}(s)
\end{aligned}
$$

we obtain

$$
\mathrm{T}_{\mathrm{wu}}(\mathrm{s})=\mathrm{T}_{\mathrm{Fwu}}(\mathrm{s})
$$

In figure 2 , the controlled output $\mathrm{z}$ can be written as

$$
\mathrm{z}=\mathrm{C}_{1}\left(\mathrm{sI}_{\mathrm{n}}-\mathrm{A}\right)^{-1}\left(\mathrm{~B}_{1} \mathrm{w}+\mathrm{B}_{2} \mathrm{u}\right)
$$

By using relation (33), we obtain $\mathrm{T}_{\mathrm{wz}}(\mathrm{s})$ from relation (34)

$$
\mathrm{T}_{\mathrm{wz}}(\mathrm{s})=\mathrm{C}_{1}\left(\mathrm{I}_{\mathrm{q}}+\left(\mathrm{sI}_{\mathrm{n}}-\mathrm{A}\right)^{-1} \mathrm{~B}_{2}\left(\mathrm{I}_{\mathrm{q}}-\mathrm{F}\left(\mathrm{sI}_{\mathrm{n}}-\mathrm{A}\right)^{-1} \mathrm{~B}_{2}\right)^{-1} \mathrm{~F}\right)\left(\mathrm{sI}_{\mathrm{n}}-\mathrm{A}\right)^{-1} \mathrm{~B}_{1}
$$

For a direct state feedback system, this transfer matrix is given by

$$
\mathrm{T}_{\mathrm{FWz}}(\mathrm{s})=\mathrm{C}_{1}\left(\mathrm{I}_{\mathrm{n}}-\left(\mathrm{sI}_{\mathrm{n}}-\mathrm{A}\right)^{-1} \mathrm{~B}_{2} \mathrm{~F}\right)^{-1}\left(\mathrm{sI}_{\mathrm{n}}-\mathrm{A}\right)^{-1} \mathrm{~B}_{1}
$$

By using the matrix inversion lemma, we can see that

$$
\mathrm{T}_{\mathrm{wz}}(\mathrm{s})=\mathrm{T}_{\mathrm{Fwz}}(\mathrm{s})
$$

Then for an unknown input observer-based controller, the transfer matrices from external disturbance $\mathrm{w}$ to the control input $\mathrm{u}$ and the controlled output $\mathrm{z}$ respectively are identical to those obtained by a direct state feedback controller.

\section{LTR design problem with an unknown input observer-based controller}

In this section, we present an LTR procedure to design an observer-based controller using the above unknown input reduced-order observer with its two parametrizations.

\section{a. Exact LTR design}

Let $\mathrm{L}_{\mathrm{t} 1}(\mathrm{~s})$ and $\mathrm{L}_{\mathrm{t} 2}(\mathrm{~s})$ be the loop transfer matrices obtained with the loop broken at (i) and (ii) in figure 2 respectively. We have 


$$
\mathrm{L}_{\mathrm{t} 1}(\mathrm{~s})=\left(\mathrm{I}_{\mathrm{q}}-\mathrm{F} \mathrm{D}_{-}^{-1}(\mathrm{~s}) \mathrm{N}_{-\mathrm{u}}(\mathrm{s})\right)^{-1}\left(\mathrm{~F} \mathrm{D}_{-}^{-1}(\mathrm{~s}) \mathrm{N}_{-\mathrm{y}}(\mathrm{s}) \mathrm{C}_{2}\left(\mathrm{sI}_{\mathrm{n}}-\mathrm{A}\right)^{-1}\left[\mathrm{~B}_{1} \mathrm{~B}_{2}\right]\right)
$$

and

$$
\mathrm{L}_{\mathrm{t} 2}(\mathrm{~s})=\mathrm{F} \mathrm{D}_{-}^{-1}(\mathrm{~s})\left[\begin{array}{ll}
\left(\mathrm{N}_{-\mathrm{y}}(\mathrm{s}) \mathrm{C}_{2}\left(\mathrm{sI}_{\mathrm{n}}-\mathrm{A}\right)^{-1} \mathrm{~B}_{1}\right) \quad\left(\mathrm{N}_{-\mathrm{u}}(\mathrm{s})+\mathrm{N}_{-\mathrm{y}}(\mathrm{s}) \mathrm{C}_{2}\left(\mathrm{sI}_{\mathrm{n}}-\mathrm{A}\right)^{-1} \mathrm{~B}_{2}\right)
\end{array}\right]
$$

For a direct state feedback, these two break points are identical and the loop transfer function is given by

$$
\mathrm{L}_{\mathrm{Ft}}(\mathrm{s})=\mathrm{F}\left(\mathrm{sI}_{\mathrm{n}}-\mathrm{A}\right)^{-1}\left[\mathrm{~B}_{1} \mathrm{~B}_{2}\right]
$$

From (32) and (39), it is easy to see that

$$
\mathrm{L}_{\mathrm{Ft}}(\mathrm{s})=\mathrm{L}_{\mathrm{t} 2}(\mathrm{~s})
$$

In order to have the same robustness with an observer-based controller than with a state feedback, Doyle and Stein [2], [3] propose to choose the loop transfer function as target loop transfer function in the LTR design : one wishes to make $\mathrm{L}_{\mathrm{t} 1}(\mathrm{~s})=\mathrm{L}_{\mathrm{Ft}}(\mathrm{s})$, i.e. $\mathrm{L}_{\mathrm{t} 1}(\mathrm{~s})=\mathrm{L}_{\mathrm{t} 2}(\mathrm{~s})$. Then, an exact LTR design is attained with the unknown input observer defined in (10) (we can use the minimal order observer defined in (22)) if

$$
\mathrm{N}_{-\mathrm{u}}(\mathrm{s})=0
$$

or

$$
\mathrm{N}_{\mathrm{u}}(\mathrm{s})=0
$$

The polynomial matrix $\mathrm{N}_{-u}(\mathrm{~s})$ and the transfer matrix $\mathrm{N}_{\mathrm{u}}(\mathrm{s})$ are called recovery matrices [10]. The polynomial matrix D_(s) being non-singular, relations (42.1) and (42.2) are equivalent. In these relations, the control input is considered as an unknown input in the design of the observer. From theorem 4, we know that the fixed poles of the obtained unknown input observer are given by the invariant zeros of the triplet $\left(\mathrm{A},\left[\begin{array}{ll}\mathrm{B}_{1} & \mathrm{~B}_{2}\end{array}\right], \mathrm{C}_{2}\right)$.

The exact LTR defined by one of the two relations (42) is achievable if assumptions A-2 and A-3 are satisfied when one replaces matrix $B_{1}$ by matrix $\left[B_{1} B_{2}\right]$, then $\left[G_{21}(s) G_{22}(s)\right]$ must be a minimum phase plant. Hence, we have solved an LTR design problem by designing an unknown input observer.

The main issue in robust control paradigm is to design a controller which tracks a reference signal in face of various types of uncertainties, which can be disturbances, measurement noise, unmodeled dynamics or unknown reference signals to be applied. It is well known that this tracking objective and all these kinds of uncertainties are related to two transfer matrices, the sensitivity function $S(s)$ and the complementary sensitivity function $\mathrm{T}(\mathrm{s})$. The robust control objectives can be formulated as the minimization of $\left\|\mathrm{W}_{\mathrm{S}}(\mathrm{s}) \mathrm{S}(\mathrm{s})\right\|_{\infty}$ and $\left\|\mathrm{W}_{\mathrm{T}}(\mathrm{s}) \mathrm{T}(\mathrm{s})\right\|_{\infty}$ where $\mathrm{W}_{\mathrm{S}}(\mathrm{s})$ and $\mathrm{W}_{\mathrm{T}}(\mathrm{s})$ are weighting functions chosen to have a trade-off between performance and robust stability. To analyze the robustness of the proposed LTR design (i.e. $\mathrm{N}_{\mathrm{u}}(\mathrm{s})=0$ ), we compare the obtained sensitivity and complementary sensitivity functions given by 


$$
\mathrm{S}(\mathrm{s})=\left(\mathrm{I}_{\mathrm{q}}-\left(\mathrm{I}_{\mathrm{q}}-\mathrm{F} \mathrm{D}_{-}^{-1}(\mathrm{~s}) \mathrm{N}_{-\mathrm{u}}(\mathrm{s})\right)^{-1} \mathrm{~F} \mathrm{D}_{-}^{-1}(\mathrm{~s}) \mathrm{N}_{-\mathrm{y}}(\mathrm{s}) \mathrm{C}_{2}\left(\mathrm{sI}_{\mathrm{n}}-\mathrm{A}\right)^{-1} \mathrm{~B}_{2}\right)^{-1}
$$

and

$$
\mathrm{T}(\mathrm{s})=-\mathrm{S}(\mathrm{s})\left(\mathrm{I}_{\mathrm{q}}-\left(\mathrm{I}_{\mathrm{q}}-\mathrm{F} \mathrm{D}_{-}^{-1}(\mathrm{~s}) \mathrm{N}_{-\mathrm{u}}(\mathrm{s})\right)^{-1} \mathrm{~F} \mathrm{D}_{-}^{-1}(\mathrm{~s}) \mathrm{N}_{-\mathrm{y}}(\mathrm{s}) \mathrm{C}_{2}\left(\mathrm{sI}_{\mathrm{n}}-\mathrm{A}\right)^{-1} \mathrm{~B}_{2}\right)
$$

with those obtained with a direct state feedback control law

$$
S_{F}(s)=\left(I_{q}-F\left(s_{n}-A\right)^{-1} B_{2}\right)^{-1}
$$

and

$$
T_{F}(s)=-S_{F}(s) F\left(s_{n}-A\right)^{-1} B_{2}
$$

If $\mathrm{N}_{-\mathrm{u}}(\mathrm{s})=0$ (or equivalently $\mathrm{N}_{\mathrm{u}}(\mathrm{s})=0$ ), we have

$$
\mathrm{S}(\mathrm{s})=\mathrm{S}_{\mathrm{F}}(\mathrm{s})
$$

and

$$
\mathrm{T}(\mathrm{s})=\mathrm{T}_{\mathrm{F}}(\mathrm{s})
$$

\section{b. Approximate LTR design with an unknown input observer-based controller}

Throughout this section, we assume that assumptions A-2 and A-3 are satisfied with matrix $\mathrm{B}_{1}$ but not with matrix $\left[\begin{array}{ll}B_{1} & B_{2}\end{array}\right]$. In this case, we cannot equal to zero the matrix $N_{u}$ (s) with respect to the stability of the closed loop, therefore we must solve an approximate LTR design with an unknown input observer. To solve this design problem with robustness and performance specifications, we minimize a recovery error $\mathrm{E}(\mathrm{s})$ given by

$$
\mathrm{E}(\mathrm{s})=\mathrm{S}_{\mathrm{F}}(\mathrm{s})-\mathrm{S}(\mathrm{s})=\mathrm{T}(\mathrm{s})-\mathrm{T}_{\mathrm{F}}(\mathrm{s})
$$

(where relation $\mathrm{S}(\mathrm{s})+\mathrm{T}(\mathrm{s})=\mathrm{I}$ is exploited). By using equations (43) and (44), the recovery error $\mathrm{E}(\mathrm{s})$ can be written as

$$
E(s)=\left(I_{q}-F\left(s I_{n}-A\right)^{-1} B_{2}\right)^{-1}-\left(I_{q}-\left(I_{q}-F_{-}^{-1}(s) N_{-u}(s)\right)^{-1} F_{-}^{-1}(s) N_{-y}(s) C_{2}\left(s I_{n}-A\right)^{-1} B_{2}\right)^{-1}
$$

Using equations (32.1) and (32.3), equation (47) becomes

$$
\mathrm{E}(\mathrm{s})=\left(\mathrm{I}_{\mathrm{q}}-\mathrm{F}\left(\mathrm{sI}_{\mathrm{n}}-\mathrm{A}\right)^{-1} \mathrm{~B}_{2}\right)^{-1}-\left(\mathrm{I}_{\mathrm{q}}-\left(\mathrm{I}_{\mathrm{q}}-\mathrm{FD}_{-}^{-1}(\mathrm{~s}) \mathrm{N}_{-\mathrm{u}}(\mathrm{s})\right)^{-1}\left(\mathrm{~F}\left(\mathrm{sI}_{\mathrm{n}}-\mathrm{A}\right)^{-1} \mathrm{~B}_{2}-\mathrm{FD}_{-}^{-1}(\mathrm{~s}) \mathrm{N}_{-\mathrm{u}}(\mathrm{s})\right)\right)
$$

and from the matrix inversion lemma, we obtain

$$
E(s)=\left(I_{q}-F\left(s I_{n}-A\right)^{-1} B_{2}\right)^{-1}-\left(\left(I_{q}-F D_{-}^{-1}(s) N_{-u}(s)\right)^{-1}\left(I_{q}-F\left(s I_{n}-A\right)^{-1} B_{2}\right)\right)^{-1}
$$

which can be written in a similar form as in [5], [7] and [10]

$$
\mathrm{E}(\mathrm{s})=\mathrm{S}_{\mathrm{F}}(\mathrm{s}) \mathrm{F} \mathrm{D}_{-}^{-1}(\mathrm{~s}) \mathrm{N}_{-\mathrm{u}}(\mathrm{s})=\mathrm{S}_{\mathrm{F}}(\mathrm{s}) \mathrm{F} \mathrm{N}_{\mathrm{u}}(\mathrm{s})
$$


Since $\mathrm{S}_{\mathrm{F}}(\mathrm{s})$ and $\mathrm{F}$ are independent of the recovery matrix $\mathrm{N}_{\mathrm{u}}(\mathrm{s})$, the minimization of $\|\mathrm{E}(\mathrm{s})\|_{\infty}$, i.e. the approximate LTR design, can be solved by a weigthed minimization of the H-infinity norm of $\mathrm{N}_{\mathrm{u}}(\mathrm{s})$. It should be noted that, in the non-minimum phase case, the minimization of $E(s)$ is not equivalent to the unweighted minimization of $\mathrm{N}_{\mathrm{u}}(\mathrm{s})$ [7]. We propose two approximate LTR design methods. In the first one, the unknown input observer-based controller is designed from (42.1), equations (22.1) and (22.3) can be used to obtain a minimal order observer. In the second method, which is optimal, we use equations (25) and (42.2).

\section{Method 1}

As alternative to equation (42.1), we can choose a matrix $\mathrm{Z}$ such that $\left\|\mathrm{N}_{-\mathrm{u}}\right\|_{\mathrm{F}}$ is minimal subject to the stability of $\left(-\alpha_{3}-Z \gamma_{3}\right)$, where $\|A\|_{F}$ is the Frobenius norm of matrix A. The Frobenius norm is used since the numerator of the matrix fraction description of $\mathrm{N}_{-\mathrm{u}}(\mathrm{s})$ is a constant matrix $\mathrm{N}_{-\mathrm{u}}(22.3)$ if the unknown input observer is of minimal order. This method is suboptimal since the polynomial denominator D_(s) is not considered.

Before giving a more practical formulation for this constrained optimization problem, we present suitable expressions for matrices $\left(\mathrm{T}_{2} \mathrm{P}_{2} \mathrm{~T}_{1}^{-1}\right), \alpha_{3}$ and $\gamma_{3}$.

Equation (15.2) can be written as

$$
\mathrm{T}_{2} \mathrm{P}_{2} \mathrm{~T}_{1}^{-1}=\left[\begin{array}{cc}
\mathrm{I}_{\mathrm{n}-\mathrm{p}} & -\mathrm{B}_{11} \mathrm{~B}_{12}^{+} \\
0 & 0
\end{array}\right]+\left[\begin{array}{c}
\mathrm{Y}_{1} \\
\mathrm{Y}_{2}
\end{array}\right]\left[\begin{array}{ll}
0 & \mathrm{I}_{\mathrm{p}}-\mathrm{B}_{12} \mathrm{~B}_{12}^{+}
\end{array}\right]
$$

where $\mathrm{Y}_{1} \in \mathrm{R}^{\mathrm{n}-\mathrm{pxp}}$ and $\mathrm{Y}_{2} \in \mathrm{R}^{\mathrm{p} \text {-mxp }}$ are arbitrary matrices. Matrices $\mathrm{T}_{1}, \mathrm{~T}_{2}$ and $\mathrm{P}_{2}$ being of full rank, matrix $\mathrm{Y}_{2}$ must be chosen such that

$$
\operatorname{rank}\left(\mathrm{Y}_{2}\left(\mathrm{I}_{\mathrm{p}}-\mathrm{B}_{12} \mathrm{~B}_{12}^{+}\right)\right)=\mathrm{p}-\mathrm{m}
$$

where $\mathrm{B}_{11} \in \mathrm{R}^{\mathrm{n}-\mathrm{pxm}}$ and $\mathrm{B}_{12} \in \mathrm{R}^{\mathrm{pxm}}$ are given by

$$
\left[\begin{array}{l}
\mathrm{B}_{11} \\
\mathrm{~B}_{12}
\end{array}\right]=\mathrm{T}_{1} \mathrm{~B}_{1}
$$

and $\mathrm{B}_{12}^{+}$is a generalized inverse of matrix $\mathrm{B}_{12}$ given by $\mathrm{B}_{12}^{+}=\left(\mathrm{B}_{12}^{\mathrm{T}} \mathrm{B}_{12}\right)^{-1} \mathrm{~B}_{12}^{\mathrm{T}}$.

From equations (16) and (51), we obtain

$$
\alpha_{3}=-\left(A_{1}-\left(B_{11} B_{12}^{+}-Y_{1}\left(I_{p}-B_{12} B_{12}^{+}\right)\right) A_{3}\right)
$$

and

$$
\gamma_{3}=-Y_{2}\left(I_{p}-B_{12} B_{12}^{+}\right) A_{3}
$$

where matrices $A_{1}$ and $A_{3}$ are given by 


$$
\left[\begin{array}{ll}
\mathrm{A}_{1} & \mathrm{~A}_{2} \\
\mathrm{~A}_{3} & \mathrm{~A}_{4}
\end{array}\right]=\mathrm{T}_{1} \mathrm{~A} \mathrm{~T}_{1}^{-1}
$$

$\mathrm{A}_{1}$ being a square matrix of dimension $\mathrm{n}-\mathrm{p}$.

From equations (22.3), (51), (54) and (55), the previous constrained optimization problem can be formulated as follows : find a matrix Y such that

$$
\left\|\mathrm{J}_{\mathrm{u} 1}+\mathrm{Y} \mathrm{J}_{\mathrm{u} 2}\right\|_{\mathrm{F}} \text { is minimal subject to the stability of }(\Delta+\mathrm{Y} \Pi)
$$

where

$$
\begin{aligned}
& \mathrm{J}_{\mathrm{u} 1}=\mathrm{B}_{21}-\mathrm{B}_{11} \mathrm{~B}_{12}^{+} \mathrm{B}_{22} \\
& \mathrm{~J}_{\mathrm{u} 2}=\left(\mathrm{I}_{\mathrm{p}}-\mathrm{B}_{12} \mathrm{~B}_{12}^{+}\right) \mathrm{B}_{22} \\
& \Delta=\mathrm{A}_{1}-\mathrm{B}_{11} \mathrm{~B}_{12}^{+} \mathrm{A}_{3} \\
& \Pi=\left(\mathrm{I}_{\mathrm{p}}-\mathrm{B}_{12} \mathrm{~B}_{12}^{+}\right) \mathrm{A}_{3}
\end{aligned}
$$

and

$$
\mathrm{Y}=\mathrm{Y}_{1}+\mathrm{Z} \mathrm{Y}_{2}
$$

Hence, $\left[\mathrm{G}_{21}(\mathrm{~s}) \mathrm{G}_{22}(\mathrm{~s})\right]$ is non-minimum phase, we obtain an approximate LTR with an unknown input reduced-order observer by solving the problem (57), i.e. $\left\|N_{-u}\right\|_{F}$ is minimal under the constraint ($\alpha_{3}-Z \gamma_{3}$ ) must be a stability matrix. With the solution $Y$, after the choice of $Y_{2}$ with respect to condition (52), the design parameters $Z$ and $\left(\mathrm{T}_{2} \mathrm{P}_{2}\right)$ are given by equations (51) and (58.5). From (52) the determination of $\mathrm{Y}$ and $\mathrm{Y}_{2}$ is equivalent to that of $\mathrm{Z}$ and $\left(\mathrm{T}_{2} \mathrm{P}_{2}\right)$.

With this procedure, the unknown input observer is of minimal order $(n-p)$, and the parameters $\mathrm{a}_{1}(\mathrm{~s})$ and $\mathrm{a}_{2}(\mathrm{~s})$ (see (10)) are given by

$$
a_{1}(s)=\left[\begin{array}{cc}
I_{n-p} & Z \\
0 & 0
\end{array}\right]
$$

and

$$
a_{2}(s)=\left[\begin{array}{l}
0 \\
I_{p}
\end{array}\right]
$$

\section{Method 2}

We propose, as an alternative to equation (42.2), to minimize $\left\|N_{u}(s)\right\|_{\infty}$ with respect to the stability of the observer. Then, the $\mathrm{H}_{\infty} / \mathrm{LTR}$ design problem can be stated as follows : under assumptions A1-A4, find $\mathrm{Q}(\mathrm{s}) \in \mathrm{RH}_{\infty}$ such that

$$
\mathrm{J}_{\infty}=\left\|\mathrm{L}_{\mathrm{u}}(\mathrm{s})\right\|_{\infty}=\left\|\mathrm{N}_{\mathrm{u}}(\mathrm{s})-\mathrm{Q}(\mathrm{s}) \mathrm{W}_{\mathrm{u}}(\mathrm{s})\right\|_{\infty}
$$

is minimal, where $\mathrm{W}_{\mathrm{u}}(\mathrm{s})$ corresponds to the $\mathrm{q}$ last columns of the stable transfer matrix $\mathrm{W}(\mathrm{s})$ defined in (28). This $\mathrm{H}_{\infty} / \mathrm{LTR}$ design problem is equivalent to a model matching which can be transformed into a standard problem with $\mathrm{H}_{\infty}$ norm minimization [8] and solved using the $\mathrm{H}_{\infty}$ control with the output 
feedback [9], [17], [18]. Unlike the procedure presented in method 1, the obtained unknown input observer (25) may be not of minimal order.

In addition, using a suitable frequency weighting matrix R(s), the designer can choose the frequency range in which the properties of the direct state feedback must be recovered. The cost function becomes

$$
\mathrm{J}_{\mathrm{r} \infty}=\left\|\mathrm{L}_{\mathrm{u}}(\mathrm{s}) \mathrm{R}(\mathrm{s})\right\|_{\infty}=\left\|\left(\mathrm{N}_{\mathrm{u}}(\mathrm{s})-\mathrm{Q}(\mathrm{s}) \mathrm{W}_{\mathrm{u}}(\mathrm{s})\right) \mathrm{R}(\mathrm{s})\right\|_{\infty}
$$

The weighting function $\mathrm{R}(\mathrm{s})$ can be selected as be shown in [7].

With cost functions $\mathrm{J}_{\infty}$ or $\mathrm{J}_{\mathrm{r} \infty}$ we minimize the recovery error $\mathrm{E}(\mathrm{s})$ or a frequency weigthing recovery error E(s) R(s) [7]. We obtain an approximate LTR, but not an exact (or asymptotic) LTR, with any state feedback control law $\mathrm{u}=\mathrm{F} \mathrm{x}$, because the transfer matrix $\left[\mathrm{G}_{21}(\mathrm{~s}) \mathrm{G}_{22}(\mathrm{~s})\right]$ is non-minimum phase [19], [20].

\section{Examples}

\section{a. Minimum phase system}

Consider the unstable minimum phase system described by

$$
\begin{aligned}
& \mathrm{A}=\left[\begin{array}{cccccccc}
-0.5 & 0 & 0 & 0 & 2 & 0 & 0 & 0 \\
0 & -2 & 0 & 0 & 0 & 3 & 0 & 0 \\
-0.6667 & 0 & -4 & -0.6667 & -1.3333 & 0 & -2 & -1.3333 \\
0.3333 & 0.6667 & 0 & -6 & 0.6667 & -0.6667 & 0 & 2 \\
0.5 & 0 & 0 & 0 & 1 & 0 & 0 & 0 \\
0 & 1.5 & 0 & 0 & 0 & -0.5 & 0 & 0 \\
0.3333 & 0 & -1 & 0.3333 & 0.6667 & 0 & -5 & 0.6667 \\
0.3333 & -0.3333 & 0 & 1 & 0.6667 & 0.3333 & 0 & -5
\end{array}\right]
\end{aligned}
$$

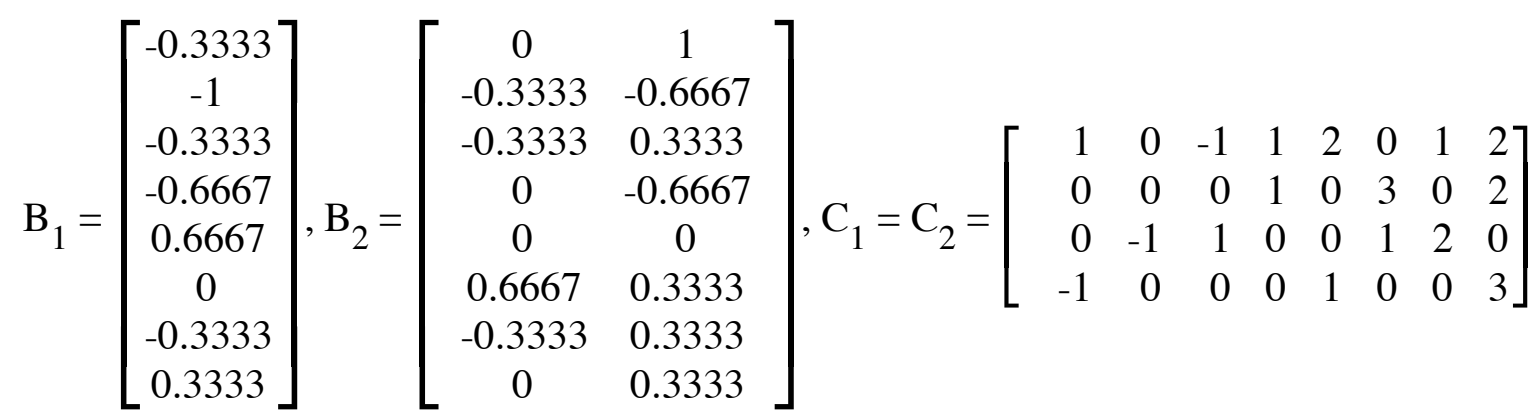

This system has the following poles : $\{-7,-6,-4,-3.5,-3,-1,1,1.5\}$. The triplets $\left(A, B_{2}, C_{2}\right)$ and $(A$, $\left[\begin{array}{ll}\mathrm{B}_{1} & \mathrm{~B}_{2}\end{array}\right], \mathrm{C}_{2}$ ) have no invariant zero.The state feedback gain matrix is given by

$$
\mathrm{F}=\left[\begin{array}{rrrrrrrr}
-23.0510 & 7.8978 & -0.5498 & 0.9969 & -124.7563 & 19.1460 & 1.7525 & 1.2351 \\
74.5590 & -18.2269 & 1.6648 & -2.0414 & 398.4068 & -43.6511 & -5.5812 & -1.7409
\end{array}\right]
$$

which is obtained by solving an $\mathrm{H}_{\infty}$ minimization problem [18]. Assumptions A-2 and A-3 are satisfied for matrix $\left[\begin{array}{ll}B_{1} & B_{2}\end{array}\right]$ 


$$
\begin{aligned}
& \operatorname{rank}\left(\mathrm{C}_{2}\left[\begin{array}{ll}
\mathrm{B}_{1} & \mathrm{~B}_{2}
\end{array}\right]\right)=\operatorname{rank}\left(\left[\mathrm{B}_{1} \mathrm{~B}_{2}\right]\right)=\mathrm{m}+\mathrm{q}=3 \\
& \operatorname{rank}\left(\left[\begin{array}{ccc}
\mathrm{SI}_{\mathrm{n}}-\mathrm{A}_{1} & \mathrm{~B}_{1} & \mathrm{~B}_{2} \\
\mathrm{C}_{2} & 0 & 0
\end{array}\right]\right)=\mathrm{n}+\mathrm{m}+\mathrm{q}=11, \forall \mathrm{s} \in \mathbb{C}, \operatorname{Re}(\mathrm{s}) \geq 0
\end{aligned}
$$

Therefore an exact LTR design with an unknown input observer is achievable. We apply three LTR procedures to recover the state feedback control law obtained with the gain matrix $\mathrm{F}$ :

a) LQG/LTR design [2], [3],

b) LTR design proposed in [13],

c) LTR design proposed in this paper (exact LTR design).

For these three designs, the performance objectives and the disturbance rejection objectives are given by the recovery of the transfer matrices given by the state feedback system (i.e. the loop transfer and the transfers from the disturbance $\mathrm{w}$ to the controlled output $\mathrm{z}$ and to the control input $\mathrm{u}$ respectively).

Figures 3 to 5 show the obtained frequency singular values. We have used the same line types for each design : "—_" for direct state feedback, "----" for method (a), "-_.-_" for method (b) and "_-" for method (c).

For methods (a) and (b), the design parameter for asymptotic LTR is $\rho^{2}=10^{-6}$. These two methods require a full-order observer ( of order $n=8$ ), whereas the proposed LTR method requires a reduced-order observer (of order $n-p=4$ ).

For method (a) which does not take the disturbance w into account, the loop transfer of the state feedback system (i.e. $\left.F\left(\mathrm{sI}_{n}-\mathrm{A}\right) \mathrm{B}_{2}\right)^{-1}$ ) is not recovered at high frequencies (e.g. figure 3 ), whereas the transfer of the state feedback system from the disturbance $\mathrm{w}$ to the controlled output $\mathrm{z}$ is not recovered at low frequencies (e.g. figure 4). The transfer of the state feedback system from the disturbance w to the control input $\mathrm{u}$ is not recovered in the whole frequency range (e.g. figure 5).

For method (b) which takes the disturbance w into account, the loop transfer of the state feedback system is not recovered at high frequencies (e.g. figure 3), whereas the transfer of the state feedback system from the disturbance $\mathrm{w}$ to the controlled output $\mathrm{z}$ is recovered in the whole frequency range (e.g. figure 4). The transfer of the state feedback system from the disturbance $w$ to the control input $u$ are not recovered in the whole frequency range (e.g. figure 5).

For methods (a) and (b), we can obtain a loop transfer recovery in the whole frequency range if the design parameter $\rho \rightarrow 0$, but this increases the required input energy. In this case, the transfer matrix from the disturbance $w$ to the control input $u$ can not be recovered.

For method (c), proposed in this paper, the three transfer matrices of the state feedback system are exactly recovered as shown in figures 3,4 and 5 .

\begin{tabular}{|c|c|c|c|c|}
\hline & ate feedback & method (a) & method (b) & method (c) \\
\hline$\left\|\mathrm{T}_{\mathrm{wu}}(\mathrm{s})\right\|_{\infty}$ & 3.5068 & 5.4857 & 337330 & 3.5068 \\
\hline$\left\|\mathrm{T}_{\mathrm{wz}}(\mathrm{s})\right\|_{\infty}$ & 3.1395 & 6.2556 & 3.1404 & 3.1395 \\
\hline
\end{tabular}

To compare the obtained disturbance rejection, we give $\left\|\mathrm{T}_{\mathrm{wu}}(\mathrm{s})\right\|_{\infty},\left\|\mathrm{T}_{\mathrm{wz}}(\mathrm{s})\right\|_{\infty}$ (see (30) and (35)) 
The disturbance rejection is better with method (c) than with method (a). For method (b), the disturbance rejection is good for the controlled output $\mathrm{z}$, whereas the disturbance $\mathrm{w}$ has a great effect on the control input $\mathrm{u}$ (110.5 $\mathrm{db}$ at low frequencies).

Method (c) gives, without using high eigenvalues of methods (a) and (b), better stability robustness and performances than these two methods. In addition, the eigenvalues of the observer in method (c) can be chosen to achieve other design objectives without damage in the disturbance rejection and the loop transfer recovery.

Then, if assumptions A-2 and A-3 are satisfied by using matrix $\left[\mathrm{B}_{1} \mathrm{~B}_{2}\right]$, we obtain, in the whole frequency range, an exact LTR by using an unknown input reduced-order observer. The disturbance rejection and the stability margins are those obtained by a direct state feedback.

\section{b. Non-minimum phase system}

Consider the following unstable non-minimum phase system

$$
\begin{aligned}
& A=\left[\begin{array}{rrrrrr}
3 & 0 & -4 & 0 & 4 & 0 \\
-1 & -4 & 1 & 7 & 0 & -7 \\
2 & 0 & -2 & 0 & 3 & 0 \\
-1 & -5 & 1 & 8 & 0 & -7 \\
2 & 0 & -1 & 0 & 2 & 0 \\
-1 & -5 & 1 & 5 & 0 & -4
\end{array}\right], B_{1}=\left[\begin{array}{rr}
1 & 0 \\
-1 & -1 \\
1 & -1 \\
-2 & -1 \\
1 & -2 \\
-1 & 0
\end{array}\right], B_{2}=\left[\begin{array}{rr}
0 & 1 \\
-1 & -1 \\
-1 & 1 \\
0 & -2 \\
0 & 0 \\
0 & -1
\end{array}\right] \\
& C_{1}=C_{2}=\left[\begin{array}{rrrrrr}
1 & -1 & -1 & 1 & 0 & -1 \\
0 & 0 & 0 & -1 & 0 & 0 \\
-1 & 0 & 1 & -1 & -1 & 1 \\
0 & -1 & 0 & 1 & 0 & -1
\end{array}\right]
\end{aligned}
$$

This system has the following poles : $\{-4,-1,1,1,3,3\}$. The state feedback gain matrix is given by

$$
\mathrm{F}=\left[\begin{array}{cccccc}
47.0888 & -9.5338 & -60.5401 & 9.1668 & 33.4966 & 0.0627 \\
-135.6089 & 10.9071 & 180.5697 & -39.2825 & -89.8290 & 28.8759
\end{array}\right]
$$

which is obtained by solving an $\mathrm{H}_{\infty}$ problem [18]. Assumptions A-2 and A-3 are satisfied for matrix $\mathrm{B}_{1}$, but not for matrix $\left[\mathrm{B}_{1} \mathrm{~B}_{2}\right]$

$$
\begin{aligned}
& \operatorname{rank}\left(\mathrm{C}_{2} \mathrm{~B}_{1}\right)=\operatorname{rank}\left(\mathrm{B}_{1}\right)=\mathrm{m}=2 \\
& \operatorname{rank}\left(\left[\begin{array}{cc}
\mathrm{sI}_{\mathrm{n}}-\mathrm{A}_{1} & \mathrm{~B}_{1} \\
\mathrm{C}_{2} & 0
\end{array}\right]\right)=\mathrm{n}+\mathrm{m}=8, \forall \mathrm{s} \in \mathbb{C}, \operatorname{Re}(\mathrm{s}) \geq 0 \\
& \operatorname{rank}\left(\mathrm{C}_{2}\left[\mathrm{~B}_{1} \mathrm{~B}_{2}\right]\right)=\operatorname{rank}\left(\left[\mathrm{B}_{1} \mathrm{~B}_{2}\right]\right)=\mathrm{m}+\mathrm{q}=4 \\
& \left\{\mathrm{~A},\left[\mathrm{~B}_{1} \mathrm{~B}_{2}\right], \mathrm{C}_{2}\right\} \text { has two transmission zeros }:\{-2,2\} \\
& \left\{\mathrm{A}, \mathrm{B}_{2}, \mathrm{C}_{2}\right\} \text { has a transmission zero }:\{2\}
\end{aligned}
$$

So an exact recovery of the state feedback control law obtained with the gain matrix $F$ is not achievable with the three LTR designs used in the previous example (i.e. methods (a) [2], [3], (b) [13] and (c)). We 
propose an approximate LTR design which minimizes the H-infinity criterion (61), called method (d).

In figures 6 to 8 , we use the same line types for each design as in figures 3 to 5 ("-_.-."” for method (d)).

For methods (a) and (b), the design parameter for the approximate LTR is $\rho^{2}=10^{-6}$. For method (d), using the parametrization of unknown input observer in $\mathrm{RH}_{\infty}$ proposed in (25), we minimize the $\mathrm{H}_{\infty}$ frequency weigthed norm of the recovery matrix $\mathrm{N}_{\mathrm{u}}(\mathrm{s})(61)$.

For methods (a) and (b), the loop transfer function of the state feedback system (i.e. F (sI $\left.\left.\mathrm{n}_{\mathrm{n}} \mathrm{A}\right) \mathrm{B}_{2}\right)^{-}$ ${ }^{1}$ ) is not recovered in the whole frequency range (e.g. figure 6). For method (d), the loop transfer function of the state feedback system is recovered at high frequencies. At low frequencies, i.e. in a frequency range inferior to $10 \mathrm{rd} / \mathrm{s}$, methods (a), (b) and (d) have the same loop transfers which are close to that given by the state feedback control law. One have not an exact recovery in this frequency range, since the triplet (A, $\mathrm{B}_{2}, \mathrm{C}_{2}$ ) has an unstable invariant zero at $\mathrm{s}=2$.

For method (a), the transfer functions of the state feedback system, from the disturbance w to the controlled output $\mathrm{z}$ and the control input $\mathrm{u}$ respectively, are not recovered in the whole frequency range (e.g. figures 7 and 8). For method (d), these two transfer functions are exactly recovered in the whole frequency range. For method (b), the transfer function of the state feedback system from the disturbance $\mathrm{w}$ to the control input $\mathrm{u}$ is not recovered in the whole frequency range. For this method, the transfer function of the state feedback system from the disturbance $\mathrm{w}$ to the controlled output $\mathrm{z}$ is recovered in the whole frequency range for the largest frequency singular values, but not for the smallest one at low frequencies.

To compare the obtained disturbance rejection, we give $\left\|\mathrm{T}_{\mathrm{wu}}(\mathrm{s})\right\|_{\infty},\left\|\mathrm{T}_{\mathrm{wz}}(\mathrm{s})\right\|_{\infty}($ see (30) and (35))

$\begin{array}{lcccc} & \text { state feedback } & \text { method }(\mathrm{a}) & \text { method }(\mathrm{b}) & \text { method }(\mathrm{d}) \\ \left\|\mathrm{T}_{\mathrm{wu}}(\mathrm{s})\right\|_{\infty} & 9.1505 & 39.5310 & 1113685 & 9.1505 \\ \left\|\mathrm{~T}_{\mathrm{wz}}(\mathrm{s})\right\|_{\infty} & 6.0285 & 41.3110 & 6.0318 & 6.0285\end{array}$

The disturbance rejection is better with method (d) than with method (a). For method (b), the disturbance rejection is good for the controlled output $\mathrm{z}$, whereas the disturbance w has a great effect on the control input $\mathrm{u}(121 \mathrm{db}$ at low frequencies).

The recovery error, i.e. $\left\|\mathrm{S}_{\mathrm{F}}(\mathrm{s})-\mathrm{S}(\mathrm{s})\right\|_{\infty}$, is given by

$\begin{array}{lcc}\text { method (a) } & \text { method (b) } & \text { method (d) } \\ 23.7772 & 23.8917 & 1.6183\end{array}$

For method (d), the minimization gives a better approximate LTR than methods (a) and (b).

\section{Conclusion}

In this paper, we have derived, in the frequency domain, an unknown input observer for FDLTI systems. The necessary and sufficient conditions of its existence are given. To design the observer, we have proposed, in the frequency domain, a straigthforward method which requires only operations on 
matrices of real numbers. This method is based on a pole placement and gives an unknown input reducedorder observer. By using the MFD, all unknown input observers are parametrized from the MFD representation and in $\mathrm{RH}_{\infty}$.

We have shown that, for minimum phase systems, if we consider the control input as an unknown input in the design of the reduced-order observer, we obtain an exact simultaneous recovery of loop transfer property and disturbance attenuation. If there exists an unstable invariant zero for the triplet (A, $\left[\begin{array}{ll}B_{1} & B_{2}\end{array}\right], C_{2}$ ), we have proposed two approximate LTR designs based on the minimization of the norm of the recovery matrix. In the first we minimize a Frobenius norm, and in the second we solve an $\mathrm{H}_{\infty}$ model matching problem.

\section{Acknoledgment}

The authors wish to thank the Guest Editors, H.H Niemann and J. Stoustrup, and the anonymous reviewers for the constructive suggestions and comments.

\section{References}

[1] Doyle J.C., "Guaranteed margins for LQG regulators", I.E.E.E. Transactions on Automatic Control, Vol AC-23, No 4, pp. 756-757, 1978.

[2] Doyle J.C. and Stein G., "Robustness with observers", I.E.E.E. Transactions on Automatic Control, Vol AC-24, No 8, pp. 607-611, 1979.

[3] Doyle J.C. and Stein G., "Multivariable feedback design: concepts for a classical/modern synthesis", I.E.E.E. Transactions on Automatic Control, Vol AC-26, No 1, pp. 4-16, 1981.

[4] Moore J.B. and Tay T.T., "Loop recovery via $\mathrm{H}_{\infty} / \mathrm{H}_{2}$ sensitivity recovery", International Journal of Control, Vol 49, pp. 1249-1271, 1989.

[5] Niemann H.H., Søgaard-Andersen P. and Stoustrup J., "Loop transfer recovery for general observer architectures", International Journal of Control, Vol 53, No 5, pp. 1177-1203, 1991.

[6] Saeki M., "H${ }_{\infty} /$ LTR procedure with specified degree of recovery", Automatica, Vol 28, No 3, pp. 509-517, 1992.

[7] Niemann H.H., Søgaard-Andersen P. and Stoustrup J., "H $\mathrm{H}_{\infty}$ optimization of the recovery matrix", Control - Theory and Advanced Technology, Vol 9, No 2, pp. 547-564, 1993.

[8] Francis B.A., "A course in $\mathrm{H}_{\infty}$ control theory", Lecture Notes in Control and Information Sciences, Vol 88, Springer-Verlag, Berlin, 1987.

[9] Dorato P., Fortuna L. and Muscato G., "Robust control for unstructured perturbations - An introduction”, Lecture Notes in Control and Information Sciences, Vol 168 Springer-Verlag, Berlin, 1992. [10] Saberi A, Chen B.M. and Sannuti P., "Loop transfer recovery : analysis and design", SpringerVerlag, Berlin, 1993.

[11] Hou M. and Müller P.C., "Design of observers for linear systems with unknown inputs”, I.E.E.E. Transactions on Automatic Control, Vol AC-37, No 6, pp. 871-875, 1992. 
[12] Darouach M., Zasadzinski M. and Xu S.J., "Full-order observers for linear systems with unknown inputs", to appear in I.E.E.E. Transactions on Automatic Control, Vol AC-39, 1994.

[13] Imai H., "Simultaneous recovery of loop transfer property and disturbance attenuation property by high gain observer", International Journal of Control, Vol 57, No 4, pp. 841-852, 1993.

[14] Anderson B.D.O. and Moore J.B., "Optimal control : linear quadratic methods", Prentice-Hall, Englewood Cliffs, 1989.

[15] Hautus M.L.J., "Strong detectability and observers", Linear Algebra and its Applications, Vol 50, pp. 353-368, 1983.

[16] Barnett S., "Polynomials and linear control systems", Marcel Dekker, New York, 1983.

[17] Glover K. and Doyle J.C., "State-space formulae for all stabilizing controllers that satisfy an $\mathrm{H}_{\infty}$ norm", Systems and Control Letters, Vol 11, pp. 167-172, 1988.

[18] Doyle J.C., Glover K., Khargonekar P.P. and Francis B.A., "State-space solutions to standard $\mathrm{H}_{2}$ and $\mathrm{H}_{\infty}$ control problems", I.E.E.E. Transactions on Automatic Control, Vol AC-34, No 8, pp. 831-847, 1989.

[19] Stein G. and Athans M., “ The LQG/LTR procedure for multivariable feedback control design”, I.E.E.E. Transactions on Automatic Control, Vol AC-32, No 2, pp. 105-114, 1987.

[20] Zhang Z. and Freudenberg J.S., "Loop transfer recovery for nonminimum phase plants", I.E.E.E. Transactions on Automatic Control, Vol AC-35, No 5, pp. 547-553, 1990. 


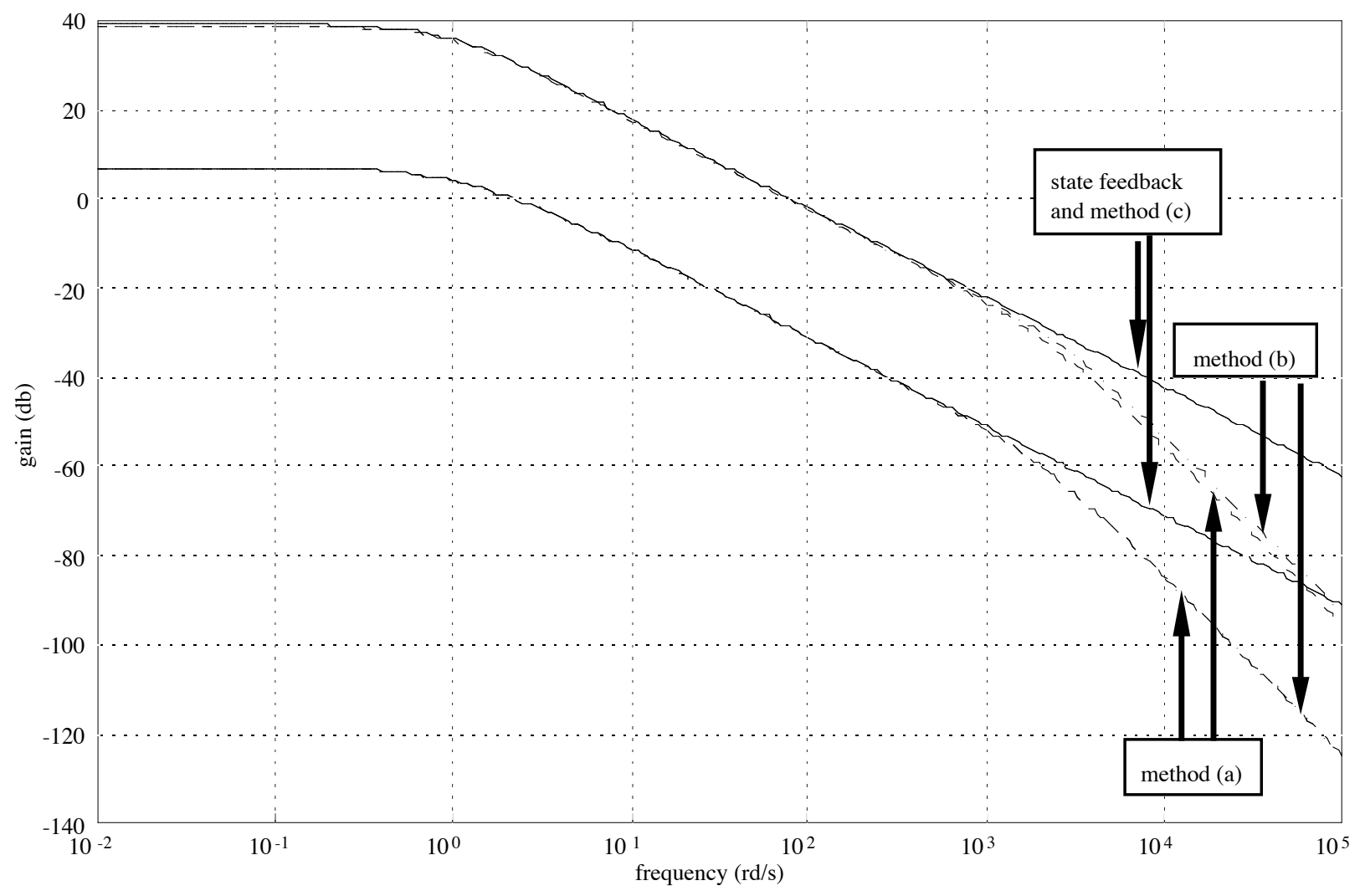

Figure 3 : frequency singular values for loop transfer matrices

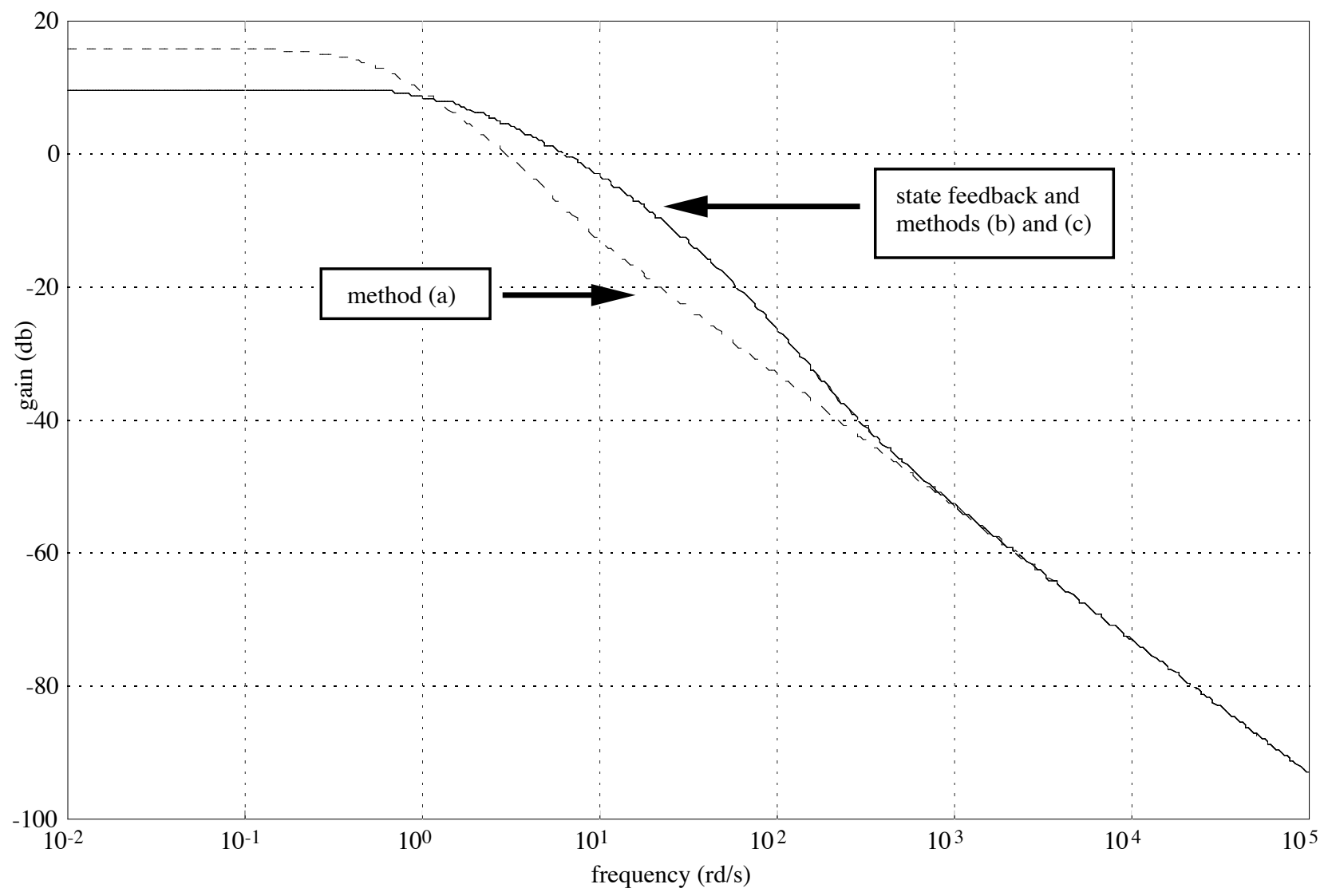

Figure 4 : frequency singular values for transfer matrices from disturbance $\mathrm{w}$ to controlled output $\mathrm{z}$ 


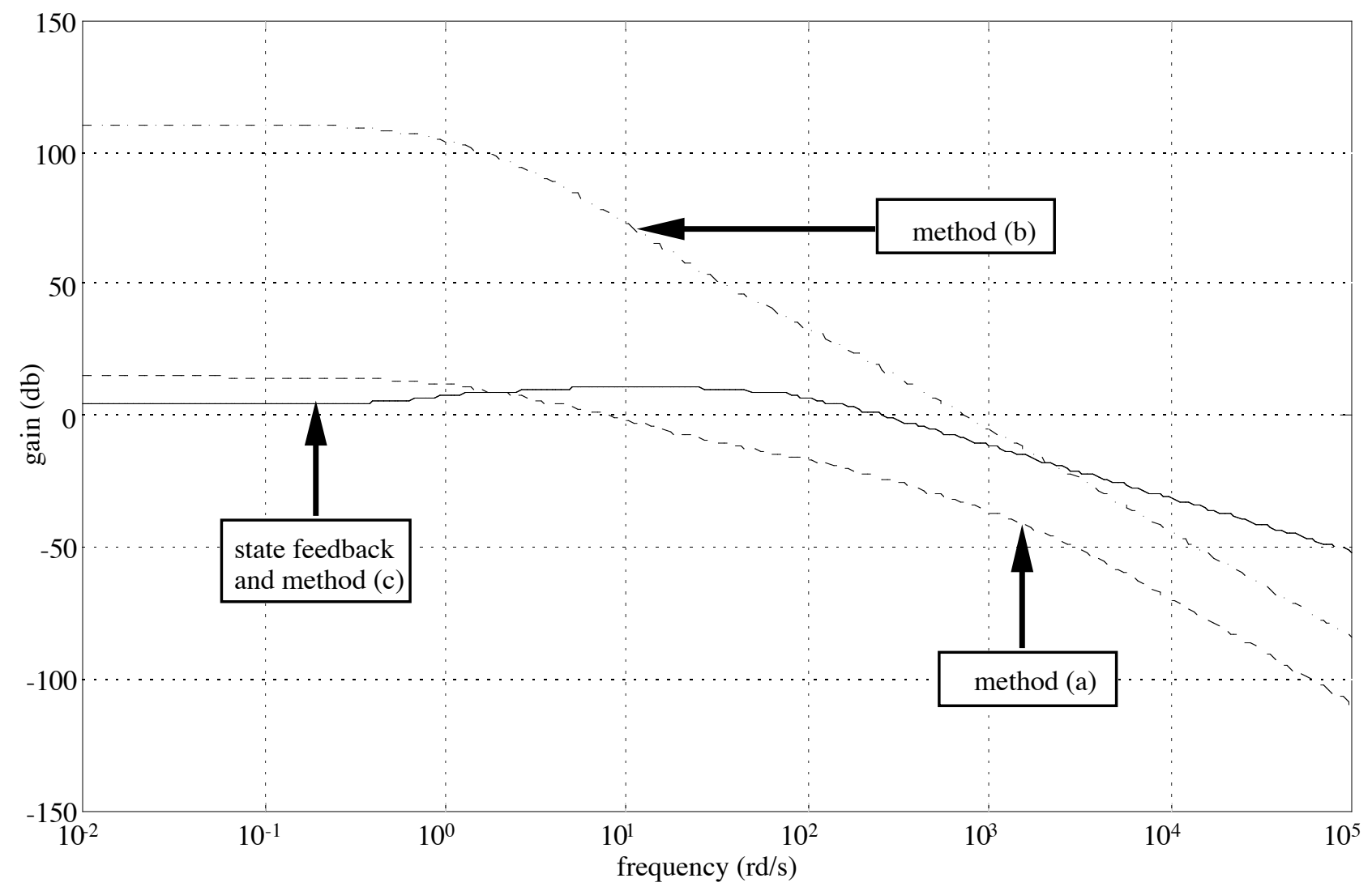

Figure 5 : frequency singular values for transfer matrices from disturbance $\mathrm{w}$ to control input $\mathrm{u}$

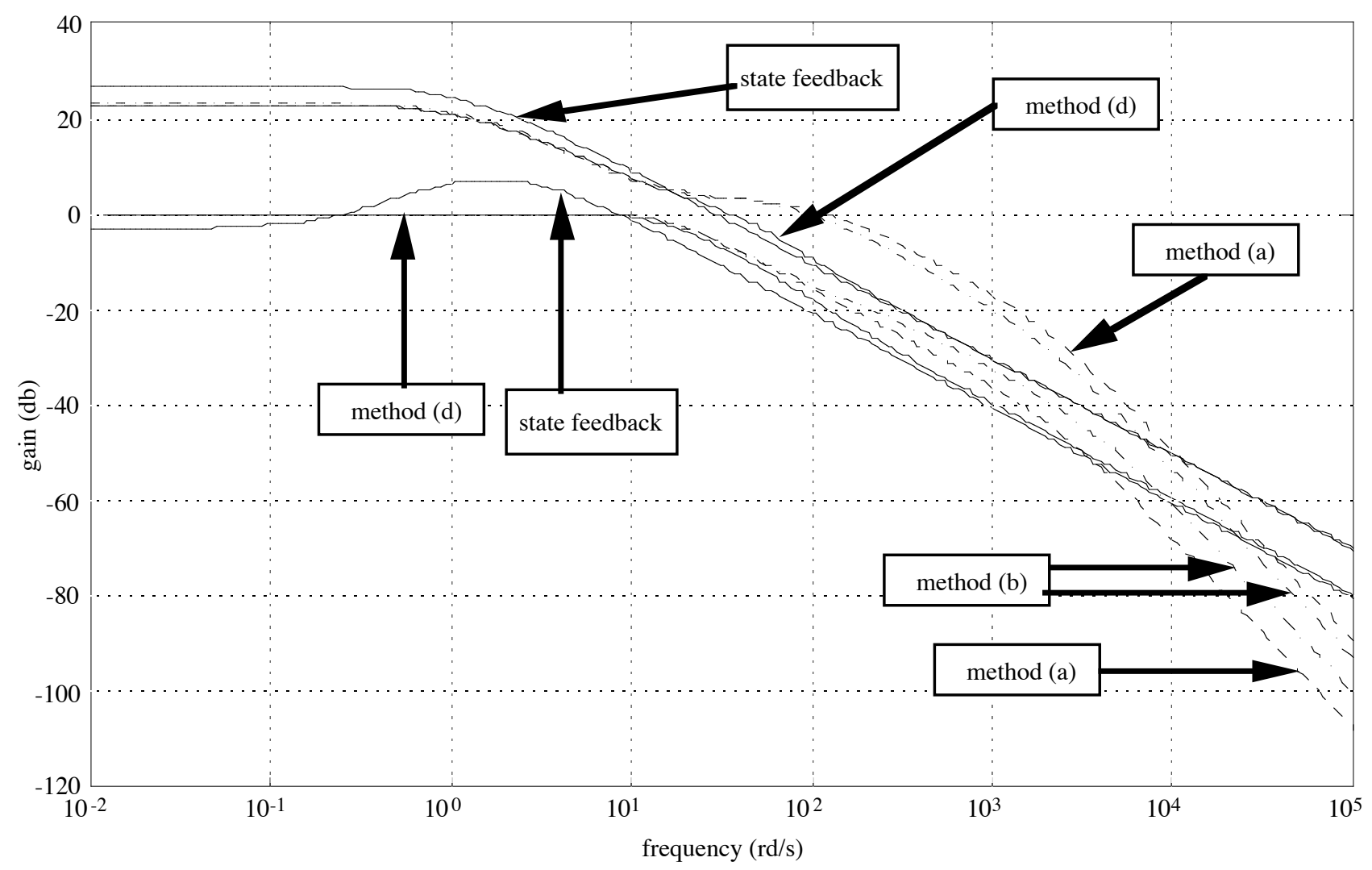

Figure 6 : frequency singular values for loop transfer matrices 


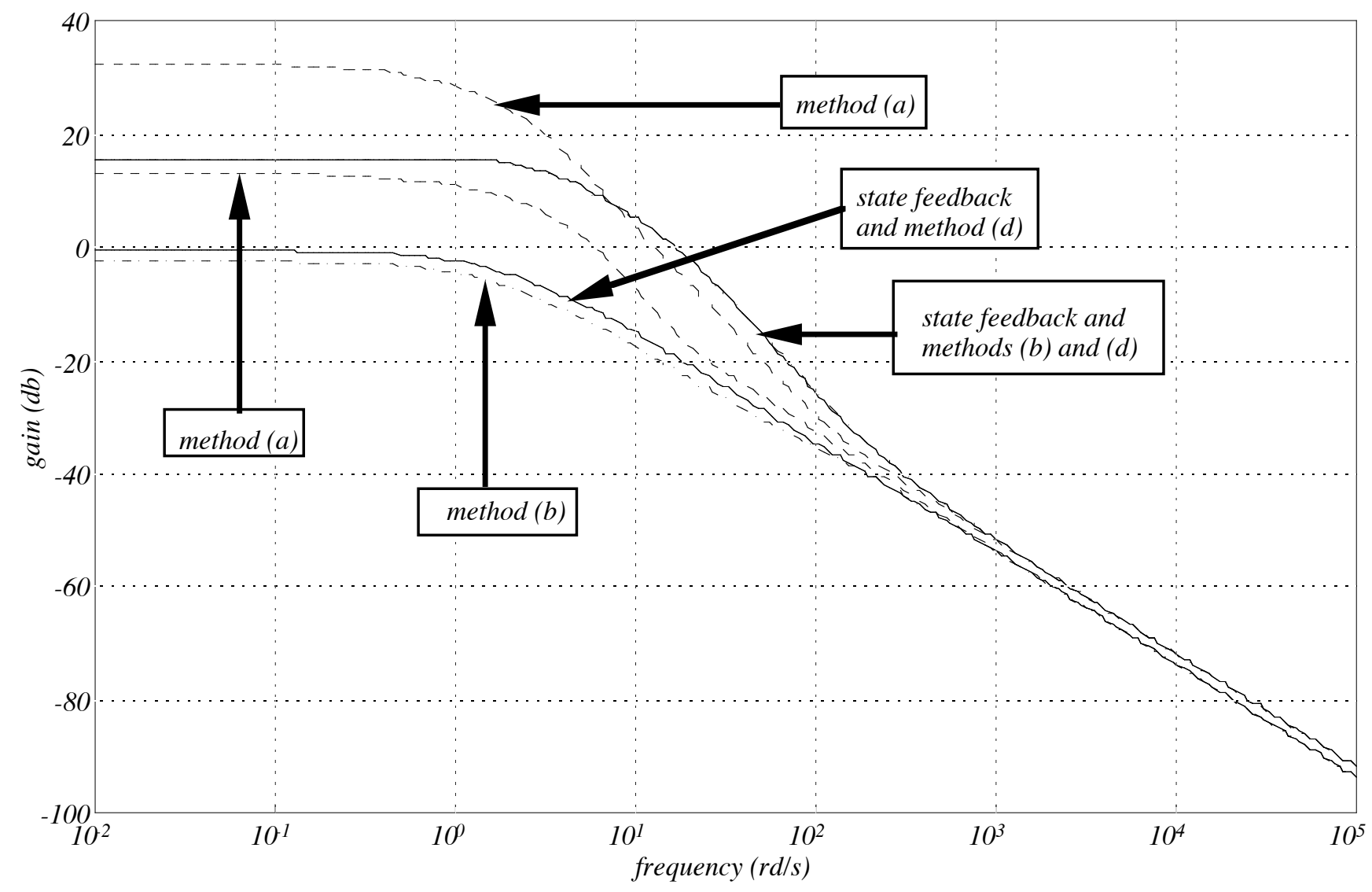

Figure 7 : frequency singular values for transfer matrices from disturbance $\mathrm{w}$ to controlled output $\mathrm{z}$

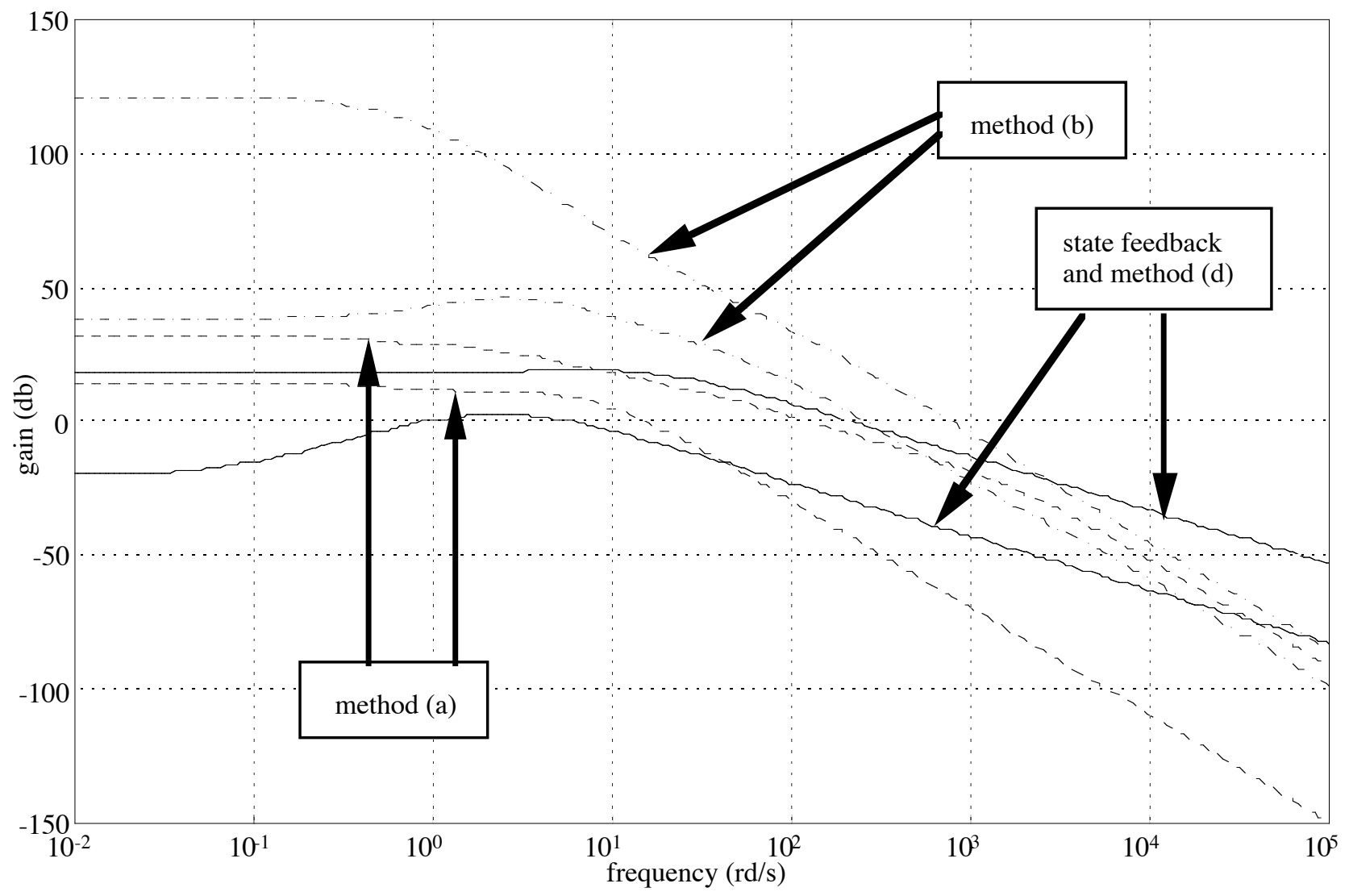

Figure 8 : frequency singular values for transfer matrices from disturbance $\mathrm{w}$ to control input $\mathrm{u}$ 